\title{
Register variation, truncation, and subject omission in English and in French ${ }^{1}$
}

\author{
LILIANE HAEGEMAN \\ University of Geneva \\ (Received 16 September 1996; revised 2 December 1996)
}

\begin{abstract}
This paper concerns the null subject phenomenon attested in abbreviated written registers in English and in French (diaries, instructions) and in informal spoken English. Neither a pro drop analysis nor a topic drop analysis will account for the incompatibility of the English null subjects with wh-preposing and with embedded contexts. Rizzi's (1994) analysis for null subjects in child production is adopted here in a slightly modified form. Like the early null subject, the (adult) null subject in abbreviated registers is an antecedentless empty category in the A-specifier of the root. Null subjects depend on the truncation of CP, which turns the specifier of IP into the highest specifier of the clause. The paper explores apparent noninitial null subjects, i.e. null subjects co-occurring with preposed adjuncts (though not arguments) and shows that these can be accounted for in terms of partial truncation within an articulated CP. The null subject is an antecedentless empty category in the (A-)specifier of an AGRprojection dominating the Topic Projection. The incompatibility with $w h$-preposing and with argument preposing is accounted for. In a more speculative vein I also consider the deletion of $b e$ in the abbreviated styles, which I claim can also be analysed in terms of truncation.
\end{abstract}

\section{Introduction}

\subsection{Aim and scope of the paper}

Languages differ with respect to whether the pronominal subject in a finite clause may be omitted or not. This parametric variation, referred to as the pro drop parameter, is illustrated in (1):

(1) (a) Italian (Io) Compro un giornale.

(b) English *(I) buy a newspaper

(c) French *(Je) achète un journal

Italian is a pro drop language: it allows a pronominal subject of a finite clause to be nonovert (1a). English and French are not pro drop languages: the pronominal

1 Earlier versions of this paper were presented on a number of occasions: the Graduate Students Conference (Manchester, 1995), the Going Romance Conference (Amsterdam, 1995), the workshop on Theory and Data (Salford, 1996), and the Conference on Grammar and Knowledge (Keio University, 1996). The paper was also presented at DIPSCO, San Raffaelle, Milan. I thank the audiences for their comments and discussion. Thanks are due to two anonymous reviewers and to Bas Aarts for comments on an earlier version of the paper. Thanks are also due to Siobhan Cottell, Paul Rowlett, and Neil Smith for help with the English data and to Natalia Kondrashova for help with the Russian data. Needless to say, none of those mentioned above can be held responsible for the remaining errors. 
subject in a finite clause cannot be nonovert $(1 \mathrm{~b}, \mathrm{c})$. The pro drop parameter is set positively for Italian: the (rich) inflection licenses the nonovert pronominal subject. In English and in French the pro drop parameter is set negatively: the inflectional system is poorer, hence a nonovert pronominal subject cannot be licensed. ${ }^{2}$

In certain noncore variants of French and English, however, nonovert subjects are found in nonfinite clauses. Early discussions of null subjects in colloquial English are found in Schmerling (1973) and Thrasher (1977).

(2) (a) Origo rather contorted: says Italy is blind red hot devoted patriotic; has thrown her wedding ring into the cauldron too. Anticipates a long war ... (Diary of Virginia Woolf, p. 6, 10 January 1936)

(b) Me dit que l'architecte Perret est désireux de passer un moment avec moi me says that the architect Perret is desirous of spending a moment with me (Léautaud, Journal particulier, 1933, p. 44)

In this paper I examine the implicit subjects in (2). The paper is written against the background of the generative model known as the Principles and Parameters model (cf. Haegeman, 1994a, for an introduction). The null subject in (2a) and (2b) cannot simply be interpreted in terms of deletion of the leftmost constituent (see Wilder, 1994; and see section 2.3). Although the majority of instances of implicit subjects in the special registers corresponds to the leftmost constituents of the clause, there are instances in which a nonovert subject co-occurs with material which normally precedes the subject:

(2) (c) Last week denounced Johnnie Cochran, ... (Guardian, 4 October 1995, 'Cast of characters', p. 2 (cols. 1-2), p. 3 (cols. 7-8))

(d) Puis se colle à moi then herself clings to me (Léautaud, Journal particulier, 1933, p. 31)

Another instantiation of the null subject in the non pro drop languages is the socalled early null subject, i.e. the implicit subject in child output. A number of analyses have been presented to account for this phenomenon. The distributional properties of the early null subject and those of the null subject in the noncore varieties of English and French are strikingly similar (Rizzi, 1994). Given the parallelism between the early null subject and the null subject in the diary style illustrated above, I will first survey the analyses of the early null subject phenomenon. I will show that both the analysis which interprets these data in terms of a missetting of the pro drop parameter (Hyams, 1986) and that which considers the

2 Unlike English, French has object pro with arbitrary reference, (i), and nonreferential pro in small clauses, (ii) (see Rizzi, 1986)

(i) Cette analyse amène prò̀ conclure que le sujet est implicite. this analysis leads to conclude that the subject is implicit 'This analysis leads people to conclude that the subject is implicit.'

(ii) Je crois [pro probable que Marie viendra].

I think pro likely that Marie will come 
phenomenon in terms of topic drop (Bromberg \& Wexler, 1995; Haegeman, 1990a, 1990b) are inadequate. At this point, Rizzi's analysis (1994) of the null subject in terms of an empty category in the specifier of the root is best compatible with the data. In order to deal with the noninitial null subject in (2c,d) I will elaborate on his analysis.

Along the lines of work by Thrasher (1977) I hope that by bringing out the grammatical properties of the null subject in specialized registers I will be able also to establish the relevance of such 'noncore' data for linguistic theory (see Akmajian, Demers, \& Harnish, 1980; Haegeman, 1988, 1990a, 1990b; Massam and Roberge, 1989; Schmerling, 1973; Stowell, 1991; Thrasher, 1977).

The paper is organized as follows: section 2 provides a survey of some of the analyses of null subjects in the non-pro-drop languages; section 3 presents data in French and in English in which the implicit subject co-occurs with adjunctpreposing; section 4 presents an analysis of these data by aligning them with other cases of subject extraction; section 5 briefly discusses be-deletion and auxiliary omission in noncore varieties of English; section 6 is the conclusion to the paper.

\subsection{Nonovert subjects and the pro drop parameter}

The positive setting of the pro drop parameter is associated with a cluster of syntactic properties. I simply list some of them here, without discussion.

1 In pro drop languages like Italian, the definite subject can occupy a postverbal position, an option not available in English or in French (but see Friedemann, 1992):

(3) (a) Ha telefonato il decano. has telephoned the dean 'The dean has phoned.'

(b) "Has telephoned the dean.

(c) *A téléphoné le doyen.

2 In Italian, an embedded subject can be moved to the matrix domain across the overt complementizer che, without giving rise to a that-trace violation. In English and French, this is not possible (Perlmutter, 1971).

(4) (a) $\mathrm{Chi}_{\mathrm{i}}$ credi che abbia telefonato $\mathrm{t}_{\mathrm{i}}$ ? $^{3}$ who believe you that have (subj.) telephoned 'Who do you think has called?'

(b) $* \mathrm{Who}_{\mathrm{i}}$ do you think that $\mathrm{t}_{\mathrm{i}}$ has telephoned?

(c) ${ }^{*} Q \mathrm{Qui}_{\mathrm{i}}$ crois tu que $\mathrm{t}_{\mathrm{i}}$ a téléphoné?

In (4b) and in (4c) the subject trace, $t_{i}$, in the embedded domain is not governed by an appropriate head governor: the complementizers that and que are inert for government.

${ }^{3}$ Following by now standard analyses, I assume that in Italian the subject is extracted from the postverbal position. As was illustrated in the text examples in (3), postverbal subjects are licit in pro drop languages. 
3 In Italian, quasi-argument subjects of weather verbs are necessarily nonovert; in English and French such subjects must be realized by a pronoun.

(5) (a) (*Ciò) piove. rains (3sg.) 'It is raining.'

(b) *(It) is raining.

(c) *(II) pleut.

Similarly, expletives in construction with a clause must be nonovert in Italian, and overt in English:

(6) (a) ("Ciò) è chiaro che Lara non partirà. 'It is clear that Lara will not leave.'

(b) "(It) is clear that Lara will not leave.

(c) "(Il) est clair que Lara ne partira pas.

4 Finally, as mentioned before, the inflectional paradigm of Italian is rich (7a): each person-number combination is associated with a distinct form, while those in English (7b) and French (7c) are poorer:

(7) $1 \mathrm{sg}$. 2 sg.

3sg.

$1 \mathrm{pl}$.

$2 \mathrm{pl}$.

$3 \mathrm{pl}$. (a) Italian parlo parli parla parliamo parlate parlano
(b) English speak speak speaks speak speak speak

(c) French parle parles parle parlons parlez parlent

The contrasts listed above are not autonomous properties of the languages in question, all can be shown to be related to the pro drop option (see Haegeman, 1994a; Jaeggli \& Safir, 1989; Rizzi, 1982, 1986, 1993).

\subsection{Referential null subjects in non-pro-drop languages}

In spite of the fact that English and French are non-pro-drop languages, finite clauses with nonovert subjects are attested. Both referential and nonreferential null subjects are instantiated in (i) restricted registers of the adult grammar, and (ii) in the early production data (for the latter see Haegeman, 1995; Hyams, 1986; Rizzi, 1994). The syntactic properties of the two types are strikingly similar (Haegeman, 1995; Rizzi, 1994). For reasons of space I will mainly focus on the adult null subject in the restricted registers.

Example (8) illustrates the omission of the pronominal subject in diaries: (8a) and (8b) are taken from English diaries, (8c) is from a French diary:

(8) (a) Origo rather contorted: says Italy is blind red hot devoted patriotic; has thrown her wedding ring into the cauldron too. Anticipates a long war ... (Diary of Virginia Woolf, p. 6, 10 January 1936) $(=(2 \mathrm{a}))$

(b) Have done 110 pages, \& those the worst. (Diary of Virginia Woolf, p. 33, 11 November 1936) 
(c) Me dit que l'architecte Perret est désireux de passer un moment avec moi me says that the architect Perret is desirous of spending a moment with me et m'invite à déjeuner chez elle avec lui le 15 . and me invites to dinner at her place with him the 15 th. (Léautaud, Journal particulier, 1933, p. 44)

In such contexts, the subject, though omitted, is syntactically represented. Evidence for this is provided in English (9) and in French (10) below. In (9) the nonovert subject of the matrix verb - represented as ec for empty category controls the nonovert subject of the italicized nonfinite predicate, as indicated by the coindexation: ${ }^{4}$

(9) (a) $[e c]_{\mathrm{i}}$ Awoke $\left[\mathrm{PRO}_{\mathrm{i}}\right.$ rested] at the Mels Packing and the temples with Terence. (Smart, Necessary secrets, p. 144)

(b) $[e c]_{\mathrm{i}}$ Walked there - $\left[\mathrm{PRO}_{\mathrm{i}}\right.$ feeling $\left._{\mathrm{i}}\right]$ light and airy. (Smart, Necessary secrets, p. 15)

In French (10) reflexive $s e_{\mathrm{i}}$ is bound by the nonovert subject of the finite verb, est ('is'); the nonovert subject also controls the nonovert subject of pensant ('thinking') in the embedded clause.

(10) $[e c]_{i} s_{i}$ 'est donné souvent l'illusion de l'amour à $P$.

refl. is given often the illusion of the love to $P$... en $\left[\mathrm{PRO}_{\mathrm{i}}\right.$ pensant $_{\mathrm{i}}$ à moi] . . .

while thinking of me

(Léautaud, Journal particulier, 1917-1930, pp. 69-70, 20.3)

Null subjects are also found in informal notes:

(11) (a) Wish you were here.

(b) Brilliant could have stayed all day.

Could see everything from wheelchair

(Visitors' book 1991, The Green, Beaumaris, Anglesey, North Wales)

(c) Préparons les copies. (French: e-mail message, 1993)

prepare (1pl) the copies

The null subject construction is also used in notices on all kinds of commercial packaging.

(12) (a) Contains carotene. (Carrot Facial Oil, The Body Shop)

(b) Se boit très frais.

refl. drinks very fresh.

'To be drunk very cold.' (Coca Cola tin)

(c) Pénètre rapidement.

penetrates rapidly (Delial sun milk)

Finally, subjects are also omitted in certain idiolects of colloquial English. Thrasher

${ }^{4}$ See Haegeman (1990a, 1990b) for additional arguments for postulating a syntactically active null subject.

In the Principles and Parameters literature, empty categories are classified according to their feature composition. The nonovert subject of a nonfinite clause is represented as PRO. 
(1977) offers a detailed discussion of these data. As also pointed out by Thrasher (1977), subjects of all three grammatical persons can be nonovert.

(13) (a) His hands full of keys, he said, 'Does the name Farriner mean anything to you?'

'Can't say it does.' . . .

Her habit of omitting pronouns from her otherwise not particularly economical speech irritated him. ${ }^{5}$

'... Couldn't get herself a man, so she was always showing what she could get. Wonder who'll get her money? Won't be me, though, not so likely.'

(Rendell, $A$ sleeping life, pp. 87-8)

(b) Came to England a couple of days ago, thought I've only got one brother, blood's thicker than water, I'll pay a visit. Called at Malbite Street, got address from Mrs Whatever-her-name-is, said it was care of Rider. Rider, I thought, I know that name, it's Geoff's friend and employer Billy. Doesn't call himself Billy any more, though. (Symons, The plot against Roger Rider, p. 67)

(c) 'Can't understand you newspaper chaps.' Mr. Corby roasted his big behind in front of the fire. 'Fill up the papers with all kinds of stuff nobody wants to read, and often miss what's right under your noses. The Gazette, now, that's a local paper - ' (Symons, 'The progress of a crime', Symons omnibus, p. 12) 'Chap as always wears an old duffle coat, long-faced chap looks as if he needs a shave. Yes, he lives up the road a couple of mile, Pebwater Farm, can't mistake it . . .' (ibid.: 130)

'No, it wouldn't do for me. Sharing everything with your neighbours, haven't even got a bit of garden to call your own except for that pocket handkerchief out there. ...' (J. Symons (1967), 'The end of Solomon Grundy', Symons omnibus, p. 30)

\section{Preceding analyses}

The question arises, of course, how the occurrences of null subjects in non pro drop languages have to be dealt with. Following Hyams' discussion of the early null subject (1986), I assume that the noncore null subject is a grammatical phenomenon (see also Hyams \& Wexler, 1993, for arguments to that effect), rather than being due to extragrammatical constraints (Bloom, 1990; Valian, 1991). I will summarize and evaluate some previous analyses for the null subject in the early French and early English production which might be invoked to account for the adult data.

\subsection{Mis-setting of the pro drop parameter}

Hyams (1986) proposes that English early null subjects are due to a mis-setting of the pro drop parameter. In the early English grammar the pro drop parameter is set positively; it is subsequently reset to its negative value. For reasons of space, I will not go into all the problems raised by the mis-setting analysis for the analysis of the

5 Observe the author's reference to 'economy' as the force behind pronoun omission. 
acquisition data (see also Haegeman, 1995; Rizzi, 1994). The empirical problems raised for the pro drop analysis of the early null subject also arise for the adult noncore variants of English and French of which the diary null subject is the prototypical example and which I will refer to from now on as null subject in diary context (abbreviated as NSD).

Before mentioning the problems with the pro drop analysis, let me point out that such an analysis for the NSD has one distinct advantage over the null topic approach which I discuss in section 2.2 : the pro drop analysis correctly predicts that only null subjects are found: object omission as in (14) would be ungrammatical even in the special registers (signalled by the diacritic \%).

(14) (a) \%The Dean has invited *(me) to the meeting

(b) \%Le Doyen* $\left(m^{\prime}\right)$ a invité à la réunion

There are a number of serious objections to a pro drop analysis of the early null subject and the NSD. The French and English diary register does not have the properties which go with the positive setting of the pro drop parameter which are listed in section 1.2. There are no definite postverbal subjects (15a); there are no violations of the that-trace filter (15b); the inflection in the diary style is no different from that of standard English or French.

(15) (a) \%*Has telephoned the Dean. $\% *$ A téléphoné le Doyen.

(b) $\% *$ Who do they think that will accept these conditions? $\%$ *Qui pensent-ils que acceptera ces conditions?

Moreover, NSDs have distributional constraints which do not apply to the pro null subject of Italian. Unlike what is the case for the null subject in the adult pro drop languages (16a), NSDs are incompatible with wh-movement $(16 \mathrm{~b}, \mathrm{c})$ :

(16) (a) Italian Che cosa hai [ec] fatto?

what have-2sg. done

(b) English \%*When will [ec] invite me again?

(c) French $\%{ }^{*}$ Quand m'invitera [ec] encore?

when me will invite again

In pro drop languages like Italian, embedded null subjects are fully grammatical (17a). French and English NSDs are a root phenomenon: the omission of the subjects in the attested examples (17b) and (17c) renders them ungrammatical. ${ }^{6}$ Thrasher (1977: 28-9) reaches the same conclusion for colloquial English null subjects.

${ }^{6}$ Frank Nuyts (p.c., 14 August 1995) signals the following example:

(i) Ten weeks since left home.

from the hand-written notes of Michael Palin's diary entry for 5 December 1988 (cover of Dutch edition: Around the world in eight days. London: BBC). I myself have not come across any such examples and will continue to assume that they are not grammatical in the diary style. Obviously, I will look further into the question. 
(17) (a) Italian Gianni canta quando [ec] è felice.

Gianni sings when is happy

(b) English He never comes when *(he) says he will.

(Smart, On the side of the angels, p. 29)

(c) French Aucune nouvelle de M.D. que *(j)'ai quittée dimanche dernier. no news from M.D. whom I have left Sunday last (Léautaud, Journal particulier, 1933, p. 77)

\subsection{Topic drop}

Based on the incompatibility of NSDs and wh-movement (16), Haegeman (1990a, $1990 \mathrm{~b})$ proposes that the NSD is an instantiation of the topic drop phenomenon. The null subject is an $\mathrm{A}^{\prime}$-trace bound by a nonovert topic operator in the CP domain (Huang, 1984). The topic drop phenomenon is also attested, for instance, in Portuguese (Raposo, 1986) and in German (Ross, 1982).

(18) (a) $O P_{i} A$ Joana viu $t_{i}$ na televisão ontem à noite. the Joana saw ec on television last night

'Joana saw (it) on television last night.'

(b) $O P_{i}$ Habe ich schon $t_{i}$ gesehen. have I already ec seen

'Have seen (it) already.'

(c) $\mathrm{OP}_{\mathrm{i}} \mathrm{O}$ José sabe que a Maria viu $\mathrm{t}_{\mathrm{i}}$ (Raposo, 1986) the Jose knows that the Mary saw ec

'Jose knows that Maria saw (it).'

As mentioned above, the topic drop hypothesis runs into an immediate problem (see also Rizzi, 1994). While subject empty categories are instantiated in the relevant register, null objects are not (cf. (14)). Second, while the NSD is restricted to the root clause, the Portuguese null topic operators may bind an embedded trace (18c). Finally, if the early null subject and the NSD instantiate the null topic operator phenomenon, it is not expected that NSDs should be able to function as quasiarguments or as expletives, since quasi-arguments and expletives do not topicalize. This expectation is not borne out: the NSD in (19a) is the subject of a weather verb; that in (19b)-(19c) functions as the anticipatory subject associated with an extraposed clause; in (19d)-(19f) the null subject corresponds to existential there:

(19) (a) Rained in the night, wind, rain and hail. (Smart, On the side of the angels, p. 27)

(b) Won't be too difficult to reconstruct his argument. (Thrasher, 1977: 44)

(c) Turns out you can't do that in Texas. (Schmerling, 1973: 582)

(d) Isn't much we can do about it. (Thrasher, 1977: 44)

(e) Aren't enough left to worry about. (Thrasher, 1977: 44)

(f) Might be an accident up ahead. (Schmerling, 1973: 582)

These objections cast serious doubt on the topic drop analysis of NSDs and of early null subjects. 


\subsection{A deletion analysis (Wilder, 1994)}

Wilder (1994: 35ff.) proposes a deletion analysis of NSDs. The account is based on an analysis of forward deletion in co-ordination, which is then extended to cover other instances of root ellipsis. In his analysis, the null subject in (20a) is like that in the second conjunct of $(20 \mathrm{~b})$ :

(20) (a) Went to the cinema.

(b) He left the office and went to the cinema.

Wilder's analysis correctly excludes object deletion:

(20) (c) *I saw Bill and invited for lunch. ${ }^{7}$

In order to rule out (21), where a post-auxiliary subject is deleted, Wilder appeals to his Head condition (22) which also governs forward deletion in co-ordination.

(21) (a) *\%Did see anyone?

(b) *Did he go there and did see anyone?

(22) Head condition

Root ellipsis is not possible in the c-command domain of an overt head. (1994: 36)

In (21a) and (21b) the null subject in the canonical subject position is governed by the auxiliary to its left. As Wilder himself admits, the ungrammaticality of (23a) is unexpected in his approach since the subject is not governed by an overt head. He points out, though, that (23a) is parallel to (23b) where the subject is deleted in a second conjunct with preposed object:

(23) (a) *This book, do not approve of.

(b) *This book, I like and that record, did not approve of.

However, as we will see below, not all preposing is excluded with null subjects. The examples in (24) are grammatical in the special registers.

(24) (a) Last night, introduced me to his mother.

(b) Hier soir, m'a présenté à sa mère.

As Wilder does not discuss the adjunct/argument asymmetry in his work, the answer to the question of what excludes the null subject with preposed complements (23) and what allows it in cases with adjunct preposing (24) remains unclear.

\subsection{Early null subjects and NSDs as antecedentless nonvariable empty categories}

As ingredients in his account of the early null subject, which I assume extends to NSDs, Rizzi (1994) proposes a more refined typology of $A^{\prime}$-traces (2.4.1), a

7 Earlier English allowed object deletion in the second conjunct:

(i) He . . took hire hond \& put _— to his mouth, as though he would haue biten it. (Arimura, 1995: 11)

For a description, see Arimura (1995) and the references cited there. 
reformulation of the ECP (2.4.2), and a theory of clausal truncation (2.4.3). I first briefly present these components of his analysis.

\subsubsection{The typology of null elements}

Following Lasnik \& Stowell (1991), Rizzi proposes that among A'-bound traces, a distinction is introduced between [ + variable] and [ - variable] traces. Variable traces involve 'quantification ranging over a possibly non-singleton set, in the latter the null element never ranges over a non-singleton set, rather it has its reference fixed to that of the antecedent' (Rizzi, 1994: 158). The trace of wh-movement is typically a variable trace; the trace associated with null operator movement, as found in easyto-please constructions, is a nonvariable empty trace:

(25) (a) $\mathrm{Who}_{\mathbf{i}}$ did you get John to talk to $\mathrm{t}_{\mathbf{i}}$ ?

(b) Bill i is easy [ $O P_{i}\left[P R O\right.$ to get John to talk to $\left.\left.t_{i}\right]\right]$

The contrast between the two types of empty categories is shown in (26) and (27):

(26) (a) *Who did you get him ${ }_{i}$ to talk to $t_{i}$ ?

(b) ${ }^{*} \mathrm{John}_{\mathrm{i}}$, is easy $\left[\mathrm{OP}_{\mathrm{i}}\right.$ [PRO to get him $\mathrm{P}_{\mathrm{i}}$ to talk to $\left.\left.\mathrm{t}_{\mathrm{i}}\right]\right]$

(27) (a) *Who did you get his ${ }_{i}$ mother to talk to $t_{i}$ ?

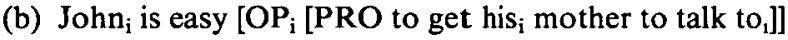

As shown in (26), both kinds of $\mathbf{A}^{\prime}$-movement - wh-movement (26a) and null operator movement (26b) - give rise to strong crossover: the movement must not cross a coindexed pronoun. This is as expected if $A^{\prime}$-traces are subject to principle $C$ : in the examples in (26) the pronoun $\operatorname{him}_{\mathrm{i}}$ will c-command and hence bind the trace. As shown in (27), though, movement of the wh-phrase also leads to weak crossover violations: the movement cannot cross a coindexed pronoun which itself is part of a constituent. Nonquantificational $A^{\prime}$-movement does not lead to weak crossover violations (see Lasnik \& Stowell, 1991, for a discussion of weak crossover).

\subsubsection{The ECP}

The empty category principle (ECP) regulates the distribution of nonovert constituents. One component of the ECP is the condition which rules that empty categories must be licensed by a governing head. This part of the ECP rules out (4b) and (4c) above. A second part of the ECP is the identification clause, which Rizzi (1994) formulates as follows:

(28) Empty Category Condition (identification)

A nonpronominal empty category must be chain-connected to an antecedent if it can be.

Based on the formulation in (28), if an empty category is the highest specifier in the structure, hence is not c-commanded by any maximal projection, then there is no potential antecedent position available. Under those circumstances, the empty category cannot be chain-connected to an antecedent and it will legitimately remain antecedentless. Observe that other principles may still rule out the empty category. 
For instance, antecedentless empty categories cannot be [+ variable]: variables need an operator to bind them. Non-variable empty categories, on the other hand, may in principle remain antecedentless as long as they occur in a position for which there is no potential antecedent.

\subsubsection{Root clauses are CPS}

For the adult grammar, Rizzi assumes that a root clause is dominated by CP, i.e. he postulates the axiom (29):

(29) (a) Root $\rightarrow \mathrm{CP}$

Perhaps (29a) can be derived. Following Chomsky (1995), one might propose that C encodes the illocutionary force of the sentence and that since all root clauses must have an illocutionary force, $\mathrm{CP}$ is enforced.

In addition to (29a) Rizzi (1997: 314) proposes (29b), a principle which derives from economy considerations (see Chomsky, 1991):

(29) (b) Avoid structure.

According to (29b), structure will only be projected when required. However, (29b) 'cannot win over the fundamental structure building principles' (Rizzi, 1997: 314). For instance, because of (29a), a fundamental structure building principle, CP must be projected. By (29b), on the other hand, syntactic structure cannot be added, for instance, to salvage a potential empty category principle violation. Thus, one cannot simply insert an abstract projection to ensure head government of the subject trace in (4b) and (4c) above (see Rizzi's paper for exemplification).

\subsubsection{The early null subject}

It is well known that early grammars of non-pro-drop languages allow for nonovert subjects in finite clauses: (30) provides some examples. As is the case for NSDs, early null subjects are incompatible with $w h$-preposing ${ }^{8}$ and with embedding.

(30) (a) Want more. (Rizzi, 1994: 1, from Hyams, 1986)

(b) Fr. A tout mangé has all eaten (Augustin, 2.0.2)

In order to account for the null subject in the English and French child grammars, Rizzi (1994) introduces the concept of structural truncation. Root clauses in the adult grammar must be projected up to the level of the complementizer, i.e. root clauses must be CPs (29a). Root clauses in the child grammar differ from the adult root clauses in that they may be truncated, i.e. the projection may stop at some level lower than CP. Finite clauses in the child grammar may be truncated, for instance, at the level IP. IP then becomes the root. In Rizzi's analysis, the early null subject is

8 This statement needs qualification, though. See Roeper \& Rohrbacher (1994); see also Haegeman (1995).

9 The data are taken from the Augustin corpus (Hamann, Rizzi, \& Frauenfelder, 1996). 2.0.2 indicates the age: 2 years, 0 months, 2 days. 
analysed as an antecedentless nonvariable empty category in the specifier of the (truncated) root, [Spec, IP].

(31) (a) IP

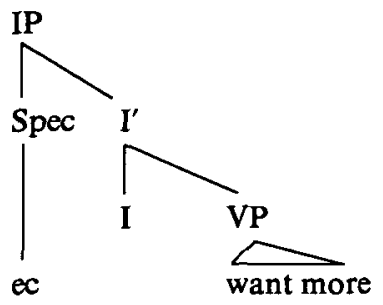

In spite of being antecedentless, a nonvariable empty category in the root [Spec, IP] of (31a) does not violate the identification clause of the empty category principle (28). Occurring in the highest specifier position of the clause, the empty category in (31a) may remain antecedentless: not being c-commanded by a potential antecedent it cannot (and hence, by (29a), need not) be chain-connected to an antecedent.

In the standard adult grammar, representations such as (31a) would be illicit; by (31a), all root clauses must be CP. On the other hand, if the CP layer is projected on top of the structure (31a), giving (3lb), an antecedentless empty category in the specifier of IP will violate the identification condition of the empty category principle (28) since the specifier of CP can host an antecedent.

(31) (b)

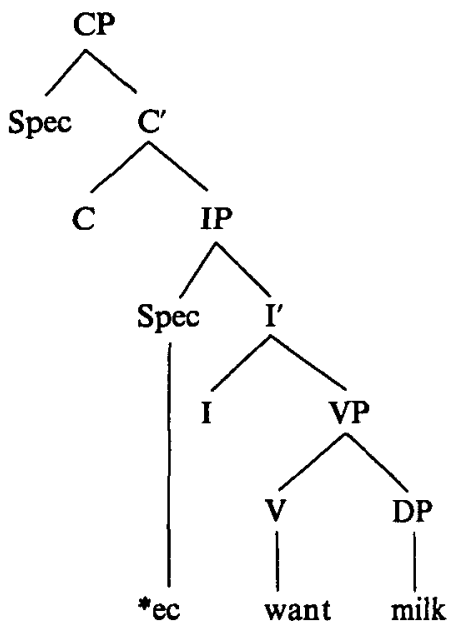

Observe that an empty category in the root [Spec, CP] can also, in principle, remain without an antecedent, since there is no higher position in the structure. However, [Spec, CP] being an $A^{\prime}$-position, it is not a suitable host for a nonvariable $A^{\prime}$-trace (Rizzi, 1994: 162). 
(31) (c)

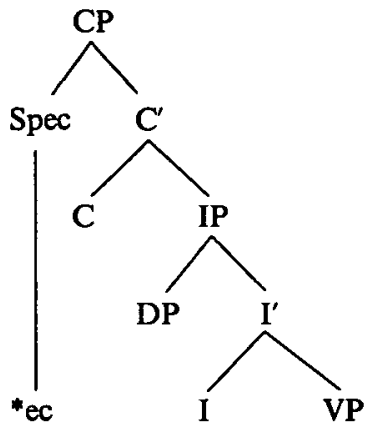

\subsubsection{Adult null subjects (NSD)}

The early null subjects are incompatible with $w h$-movement and they only occur in root clauses. The same distributional properties are observed for NSDs (see section 2.1). Given the similarities in distribution between the early null subject and the adult NSD, I will pursue the hypothesis that the NSD in the adult register is also an antecedentless nonvariable empty category in the specifier of IP, with the functional projection $\mathrm{CP}$ being truncated.

Obviously, the question arises of what legitimates truncation. One type of answer to this question was developed in Haegeman (1994b). I proposed there that (29a) is not a primitive of the grammar but can be derived from more elementary concepts. For instance, we might assume, following Enç (1987), Guéron \& Hoekstra (1988, 1992), that $T^{\circ}$ (the Tense head) has to be anchored to the context, and that this is achieved by the intermediary of $\mathrm{C}$, enforcing the presence of $\mathrm{C}^{\circ}$ whenever $\mathrm{T}^{\circ}$ is available. A parallel, but slightly more general, way of looking at (29a) is to say that the $\mathrm{CP}$ layer in the clause functions as a generalized context anchor, i.e. CP mediates in establishing all discourse relations (i.e. for reference assignment, tense interpretation, etc). Unmediated anchoring could be called deictic anchoring: here there is direct linking of the clausal constituent to the discourse, independently of $\mathrm{CP}$. The axiom (29a), that the root is CP, might then be due to the restriction that in the adult grammar discourse relations cannot be established by deictic anchoring, but that they must be mediated by $\mathrm{C}^{\circ}$. For the early grammar, Haegeman (1994b) proposes that the child does not have to use the anchoring via $\mathrm{C}^{\circ}$, but may have recourse to deictic anchoring, i.e. unmediated anchoring. What would then mature is anchoring via $\mathrm{C}^{\circ}$, which replaces deictic anchoring. Pursuing this line of reasoning, one may say that the abbreviated registers also dispense with anchoring via $\mathrm{C}^{\circ}$ and that, given the restricted discourse context, they deploy deictic, unmediated anchoring. For the role of the discourse in legitimizing the deletion see also Thrasher (1977: 14ff.).

An alternative approach to truncation (Rizzi, 1996 class lectures) would be to assume that the truncation of $\mathrm{CP}$ in the child grammar is a function of the general 
economy principles which restrict projection of structure (29b). It could be proposed that in the child grammar (29b) is stronger than (29a), while in the adult grammar (29a) wins out over (29b). In view of the fact that economy considerations ('brevity') clearly play a part in the abbreviated registers, one might then suggest that there too, (29a) is overruled by economy considerations (29b). The adult registers allowing for the null subject typically belong to abbreviated types of writing/speech; the clausal truncation is the structural reflex of this economy. I will not decide between these options here.

Returning now to the analysis of null subjects outlined above, it is clear that the observed incompatibility of early null subjects and of NSDs with wh-preposing (16b, c) and with embedded clauses $(17 \mathrm{~b}, \mathrm{c})$ is expected. In sentences with wh-preposing and in embedded clauses, the CP level must be projected. If CP is projected, then the specifier of CP may host an antecedent and by the identification clause of the ECP (28), the nonvariable empty category in [Spec, IP] will not be allowed to remain antecedentless (cf. (31b)).

The proposal also predicts that only subjects will be nonovert (cf. (14)).

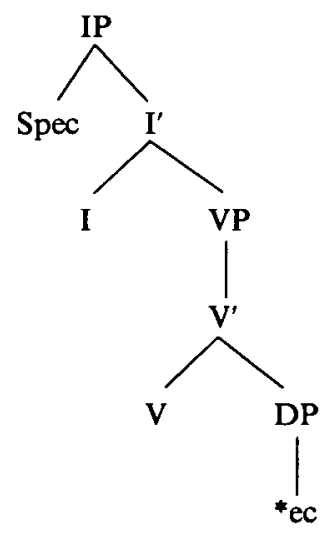

In (32) the antecedentless empty category occupies the object position. The representation violates the identification clause of the empty category principle (28): the nonvariable empty category can, hence must, be identified, i.e. chain-connected to an antecedent. [Spec, IP], the subject position, is a c-commanding position; hence it can host the antecedent of the empty category. By (28), again, the nonvariable empty category cannot remain antecedentless.

Given the distributional parallelisms between early null subjects and adult NSDs, I have extended Rizzi's analysis to the adult NSD. In abbreviated speech and writing the clausal projection can be truncated, thus allowing the specifier of IP to host an antecedentless nonvariable empty category. An empirical prediction of this analysis is that the null subject in the special register has to be the leftmost constituent of the clause. The availability of another constituent to the left of the antecedentless empty category will necessitate the projection of higher structure. If a category is projected dominating IP, there will be an antecedent position available and the nonvariable 
empty category in [Spec, IP] cannot remain antecedentless by the ECP (28). At first sight, this prediction is borne out by the data in (33):

(33) (a) *That book, don't like (Wilder, 1994: 36-7)

(b) *More problems don't need (Thrasher, 1977: 83)

Although the above examples are indeed ungrammatical, null subjects may co-occur with preposed adjuncts, as already discussed in section 2.3 . I repeat the relevant examples here for the reader's convenience:

(34) (a) Last night, introduced me to his mother.

(b) Hier soir, m'a présenté à sa mère.

A preliminary study of the relevant material reveals that by no means all null subjects in abbreviated speech and writing in French and in English are initial. I discuss these findings in the next section.

\section{Noninitial null subjects}

In a corpus of abbreviated writing, NSDs occur with preposed constituents in English (section 3.1) and in French (section 3.2). ${ }^{10}$ Significantly, the preposed constituent in the NSD sentence is always an adjunct; NSDs co-occurring with preposed arguments are not attested. The same distributional constraints apply to the early null subject (Haegeman, 1995). I limit the discussion to NSDs here, for reasons of space. In the following sections I provide some illustrations of what appear to be noninitial NSDs in English (3.1) and in French (3.2).

\subsection{English NSD}

In Samuel Pepys' diary, written in the seventeenth century, null subjects sometimes co-occur with topicalized adjuncts. In The shorter Pepys (selected and edited by Robert Latham, from the diary of Samuel Pepys), the passage covering the period of January-April 1660 contains 19 null subjects, 5 of which co-occur with sentenceinitial material. Sentence (35a) is an example of an initial null subject; (35b-f) are examples of NSDs with a preposed constituent.

(35) (a) Went to Mr. Gunnings church at Exeter house, where he made a very good sermon upon these words: That . . (Pepys, 1 Jan.)

(b) At noon went by water with Mr Maylard and Hales to the Swan in Fischstreete at our colly-feast, where we were merry ... (Pepys, 20 Jan.)

(c) So parted; . . . (Pepys, 20 Jan.)

(d) In the morning, entended to have gone to Mr Crews to borrow some money. (Pepys, 21 Feb.)

10 In Haegeman (1990b) I already signal the following case without discussion:

(i) ?After I had left the party, saw no one.

For the parallel noninitial null subject in the acquisition data see Friedemann (1992), and especially Haegeman (1995). 
(e) At night sent a packet to London. (Pepys, 18 April)

(f) Returning, met with Mr. Gifford, who took me . . (Pepys, 3 Mar.)

With respect to some of the examples above, it might be argued that the preposed material is structurally independent of the clause (35f), but examples such as (35b) with an initial PP at noon seem to be uncontroversial evidence for the co-occurrence of a null subject and a topicalized PP adjunct.

In the more recent English diaries I have looked at (see list of corpus material) I have so far found no examples of null subjects co-occurring with preposed adjuncts, but this is perhaps due to the fact that I have consulted a very small sample. In a 1,000-word survey of the protagonists of the O. J. Simpson trial in the British newspaper The Guardian the phenomenon is attested. The text contains 45 root clauses. In 27 of these there is no preposing; 16 of these sentences have a null subject (e.g. (36a)), 6 of which occur in the second conjunct of a co-ordinated clause (36b), a phenomenon which $I$ do not consider in this paper. The remaining 18 root clauses contain preposed material; among these, 6 have a null subject $(36 \mathrm{c}-\mathrm{h})$. None of the 20 embedded sentences has a nonovert subject.

(36) (a) Won some public sympathy when her ex-husband sued for custody of their two children during the trial.

(b) but was held largely responsible for unfocused prosecution presentation.

(c) Under cross-examination admitted a string of bungles . . .

(d) After Cochran's blistering closing argument, declared with rare hyperbole . . .

(e) Last week denounced Johnnie Cochran, ... .

(f) Lugubrious figure, initially regarded as a prosecution's token black lawyer, proved its most accomplished court-room performer.

(g) Little known, feisty New York attorney imported to attack prosecution scientific evidence, emerged as a defence star.

(h) Mustachioed advertising executive, father of 'forgotten' victim Fred Goldman, has lambasted Simpson team in several embittered, but dignified, out of court attacks. (Guardian, 4 October 1995, 'Cast of characters', p. 2 (cols. 1-2), p. 3 (cols. 7-8))

$I$ interpret the initial constituents in $(35 f-h)$ as predicative adjuncts. Even if one were to consider these constituents as the subjects (unlikely, given the commas), $(35 \mathrm{c}-\mathrm{e})$ are undoubtedly instances in which a null subject occurs in a clause with preposed material. This means that at least 3 out of the 18 sentences with preposing have a null subject (and on a more generous count this figure rises to 6/18).

Although a null subject is possible with a preposed adjunct, it apparently remains the marked option: 8 out of the 18 sentences with preposed material have a pronoun subject, and 4 out of the 18 sentences have a lexical DP subject. Without preposed material we find 10 out of 27 cases with a lexical DP subject, 16 instances of null subjects and only one instance of a pronoun subject. Assuming some version of the avoid pronoun principle (see Cardinaletti \& Starke, 1993), another instantiation of the principle of economy (cf. (29b)), this suggests that in the register where null subjects are licit, they in fact are favoured over pronouns in the absence of preposed material. When there is preposed material, though, the null subject becomes a 
marked, i.e. probably more costly, option, and the pronoun, being less marked, hence less costly, will be preferred.

For spoken English, Thrasher (1977) provides the following contrast:

(37) (a) Next time you get to Kobe, want you to buy me an umbrella. (1977: 80)

(b) *More problems don't need (1977: 83)

The null subject is compatible with the preposed adjunct in (37a) and is ungrammatical with a preposed argument in (37b).

This contrast is confirmed by the material which I have examined: all the examples of apparently noninitial NSDs concern adjunct preposing. There are no examples in the material with a topicalized argument. From this I conclude that (37b) would also be ungrammatical in written English.

\subsection{French NSD}

In Léautaud's 1933 Journal particulier, 10 of 102 examples of nonovert subjects, i.e. around 10 per cent, co-occur with a preposed constituent. The list in (38) is exhaustive. Again there are no examples of a preposed argument.

(38) (a) Puis se colle à moi. (Léautaud, Journal particulier, 1933, p. 31) then clings to me

(b) De nouveau me tend sa bouche. (ibid.)

again me presents her mouth

(c) Tout de suite m'a parlé de ma visite chez elle (ibid., p. 45) immediately me has talked about my visit to her

(d) Après bien de conversation, étendue sur son divan, me demande de venir after some conversation stretched out on her sofa me asks to come près d'elle. (ibid., p. 50)

to her

(e) Etant allée p. m'a appelé: ... (ibid., p. 66) being gone p. me has called

(f) Comme je partais sans avoir parlè de rien, m'a couru après as I left without having talked about anything me has run after pour me rappeler. (ibid., p. 70)

to me remind

(g) Comme je parle de Billy..., me dit qu'il lui a semblé que...(ibid., p. 76) as I talk about Billy me says that to her it seemed that

(h) Jamais ne se serait attendue à cela. (ibid., p. 96) never herself would have expected this

(i) Ce soir, pour la premiere fois, m'a mis la langue. (ibid., p. 119) this evening for the first time me has put the tongue

(j) Comme je l'invitais après déjeuner à une petite séance aulit vers quatre as I her invited after dinner for a little séance in bed around four heures, m'a opposé toutes sortes de raisons pour me refuser. (ibid., p. 124) hours me has opposed all sorts of reasons to me refuse 


\subsection{Adjunct/argument asymmetries}

The attested data displayed in the above sections, though of no statistical value, seem to confirm the contrast shown in Thrasher (1977): the NSD is not excluded with preposed adjuncts, though it is excluded with preposed objects. This conclusion holds both for English and for French. I will try to reconcile these data with the truncation analysis outlined above.

\section{The analysis}

\subsection{The problem and some proposals}

(39) illustrates the problematic examples for the account of NSDs in terms of antecedentless empty categories. If the null subject is an antecedentless category, then one would expect the examples in (39) to violate the ECP (28).

(39) (a) Last week ec denounced Johnnie Cochran, . .

(Guardian, 4 October 1995, 'Cast of characters', p. 2 (cols. 1-2), p. 3 (cols. 7-8))

(b) puis ec se colle à moi. (Léautaud, Journal particulier, 1933, p. 31)

then clings to me

One option would be to relate the compatibility of the preposed constituents with null subjects to the intrinsic properties of the preposed constituents. In this vein, it could be argued that the preposed elements are adjuncts, and that, being nonarguments, they cannot function as antecedents for subject - i.e. argumental - empty categories. Such an explanation would not be able to exclude the examples in (40), though, in which $w h$-adjuncts are seen to be incompatible with the NSD. There are no examples of preposed $w h$-phrases and NSDs in the material I examined.

(40) (a) $\% *$ When will come back?

(b) $\% *$ Quand reviendra?

when will return

\subsection{Adjunction}

If the preposed constituent is compatible with the NSD, then we have to disqualify the preposed adjunct somehow as an antecedent. One might propose that the preposed constituent fails to qualify as an antecedent for the empty subject because it is in an adjoined position (Lasnik \& Saito, 1984), and that adjoined constituents are not potential antecedents for the trace in [Spec, IP]. The tree in (41) is a schematic representation:

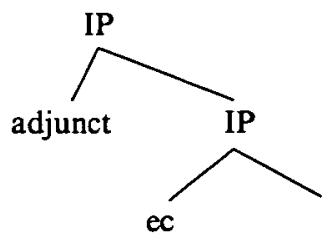


The question would arise, though, why a c-commanding adjoined constituent would be disqualified as a binder. Moreover, empirical data suggest that adverbial adjuncts and preposed constituents are not merely adjoined to projections but that they are associated with their own functional head. I will consider the evidence briefly in what follows. The arguments against adjunction will also lead us to postulate a richer structure for CP. For a generalized approach to the syntax of adverbials along these lines I refer the reader to Cinque (1995).

\subsubsection{That-trace violations and preposed adjuncts (see Bresnan, 1977; Culicover, 1991; Rizzi, 1993)}

A mere IP-adjunction analysis for preposed constituents is problematic when we consider the English data in (42):

(42) (a) *This is a law which I think [CP that [IP $t$ will be approved next week]]

(b) This is a law which I think [CP $0_{\text {AGR }}$ [IP $t$ will be approved next week]]

(c) This is a law which I think [CP that next week [IP $t$ will be approved]]

Example (42a) is ungrammatical, due to a that-trace violation: subject extraction from the lower clause across the complementizer that is illicit. The complementizer that is inert for head government, leaving the subject trace ungoverned (cf. $(4 \mathrm{~b}, \mathrm{c})$ ). To rescue the sentence, the overt complementizer has to be replaced by the nonovert variant which carries $A G R$ features (Rizzi, 1990), $0_{A G R}$ in (42b). In (42c) the overt complementizer is present but the insertion of the adjunct next week leads to an improvement of the sentence. If the adjunct were merely adjoined, it is not clear how it rescues the subject trace. What is lacking in that-trace violations $((4 b, c),(42 a))$ is a head governor for the nonovert subject. Since the insertion of the adjunct improves the sentence, this suggests that the preposed adjunct is associated with a head which, unlike that, is not inert for government and is capable of licensing the subject trace.

If preposed adjuncts are associated with specialized projections, this leads us to postulate a more articulated structure for the CP domain, in which $\mathrm{CP}$ is decomposed into a number of functional projections. I follow Rizzi's (1997) analysis here (see Bresnan, 1977; Browning, 1996; Culicover, 1991; Müller \& Sternefeld, 1993; Nakajima, 1996; Rizzi, 1993). Rizzi proposes that in general the head C should be decomposed into two functional heads, Force ${ }^{\circ}$, which encodes the illocutionary force of the clause, and $\mathrm{Fin}^{\circ}$, which encodes finiteness. I refer the reader to his paper for motivation of the 'split CP'. In addition, as illustrated in (42c), the CP domain may also contain specialized projections associated with topicalized and focalized material. Rizzi discusses (42c) as follows:

When the Topic-Focus field is activated by a preposed adverbial, force and finiteness must split, and we get a representation like [42d]. If the subject is extracted, as the lower [abstract head] expressing Fin ${ }^{\circ}$ can be associated with Agr, we get [42c]; $t$ is properly governed by Fin $^{\circ}$ with the Agr specification; . . I will assume here that Fin ${ }^{\circ}$ can move head to head to the next available head, here Top ${ }^{\circ}$, yielding representation [42d] and from that position it can properly govern $t^{\prime}$, thus satisfying the ECP. (Rizzi, 1997: 313) 
(42) (d) ForceP

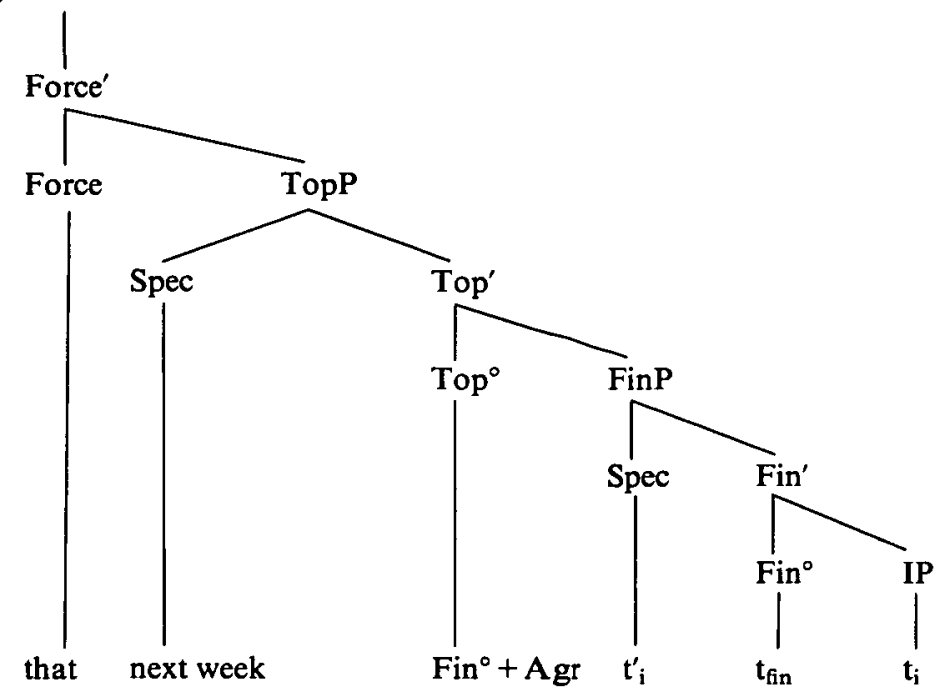

The preposed adjunct next week provides the head which will govern the subject trace $\left(t_{i}\right)$. That is no longer the functional head which is relevant for the proper government of the subject trace. The finiteness head $\left(\right.$ Fin $^{\circ}$ ) is separately projected; the subject moves via [Spec, Fin] where it triggers agreement. Carrying Agr features, Fin $^{\circ}$ ensures that the subject trace $\left(t_{i}\right)$ is properly governed. By the incorporation of Fin $^{\circ}$ to Top $^{\circ}$ the intermediate trace $t_{i}^{\prime}$ in [Spec, Fin] is also properly governed. The incorporation of $\mathrm{Fin}^{\circ}$ to $\mathrm{Top}^{\circ}$ is an instantiation of the more general option for the incorporation of a zero complementizer (represented by 0 in (43) below) to a higher head. Rizzi (1997: 320) proposes that it is the same process which also accounts for the pattern in (43):

(43) (a) I didn't expect [0 [John could come]]

(b) * 0 [John could come]] is likely.

(c) *[0 [John could come] I didn't expect.

Following Pesetsky (1995: 8), Rizzi assumes that in English the null finite complementizer is affixal and incorporates to a higher head, $V^{\circ}$ in (43a). In the antiadjacency example in (42c) the agreeing Fin $^{\circ}$ incorporates to Top ${ }^{\circ}$.

\subsubsection{Preposing and Subject-Auxiliary Inversion}

Further support for the idea that preposed adjuncts are associated with a functional head is obtained from the interaction of negative inversion and adjunct preposing in (44):

(44) (a) I swear that on no account will I write a paper during the holidays.

(b) I swear that during the holidays I will write a paper.

Example (44a) illustrates negative inversion; (44b) illustrates adjunct topicalization. I assume that the specifier of the Focus Phrase (FocP) hosts, among others, the preposed negative constituent in negative inversion, and that its head hosts the 
inverted auxiliary in (44a). Continuing to adopt Rizzi's analysis, the specifier of the topic projection hosts the preposed PP during the holidays in (44b).

As shown by the pair (45a-b), negative inversion and topicalization are compatible as long as the topicalized constituent precedes the inversion structure.

(45) (a) I swear that during the holidays on no account will I write a paper.

(b) *I swear that on no account will during the holidays I write a paper.

Assuming that topicalization is associated with a specific functional projection, the contrast between (45a) and (45b) can be related to the Head movement constraint, which says that in the course of movement a head X cannot skip an intervening head Y (Haegeman, 1994a: ch. 12 for discussion). The diagrams in (46a) and (46b) below represent the grammatical (45a) and the ungrammatical $(45 \mathrm{~b})$ respectively:

(46)

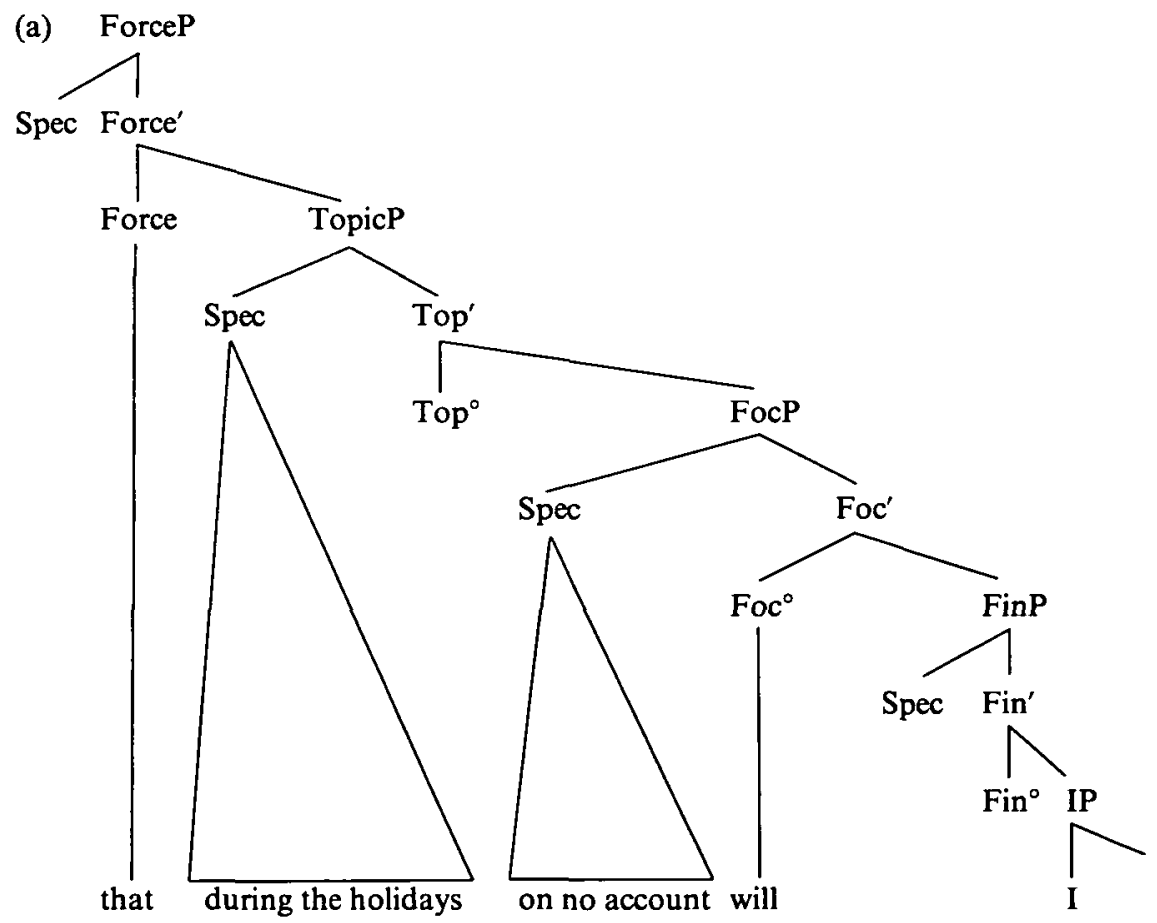

In (46a) the auxiliary will moves to $\mathrm{Foc}^{\circ}$ via Fin ${ }^{\circ}$. Top does not intervene in the movement. Representation (46b) is ungrammatical. In order to reach Foc $^{\circ}$ the auxiliary will has to skip the intervening head Top ${ }^{\circ}$. If we assume that the auxiliary cannot move to Top $^{\circ}$ (Topicalization does not give rise to Subject-Auxiliary Inversion), or, minimally, that Top $^{\circ}$ does not allow the auxiliary to move through it (Rizzi, 1997: 288), then (46b) violates the HMC: Top ${ }^{\circ}$ blocks the head movement to Foc $^{\circ}{ }^{11}$

11 For further discussion of the interaction of topicalization and negative inversion, see Haegeman (in preparation). 


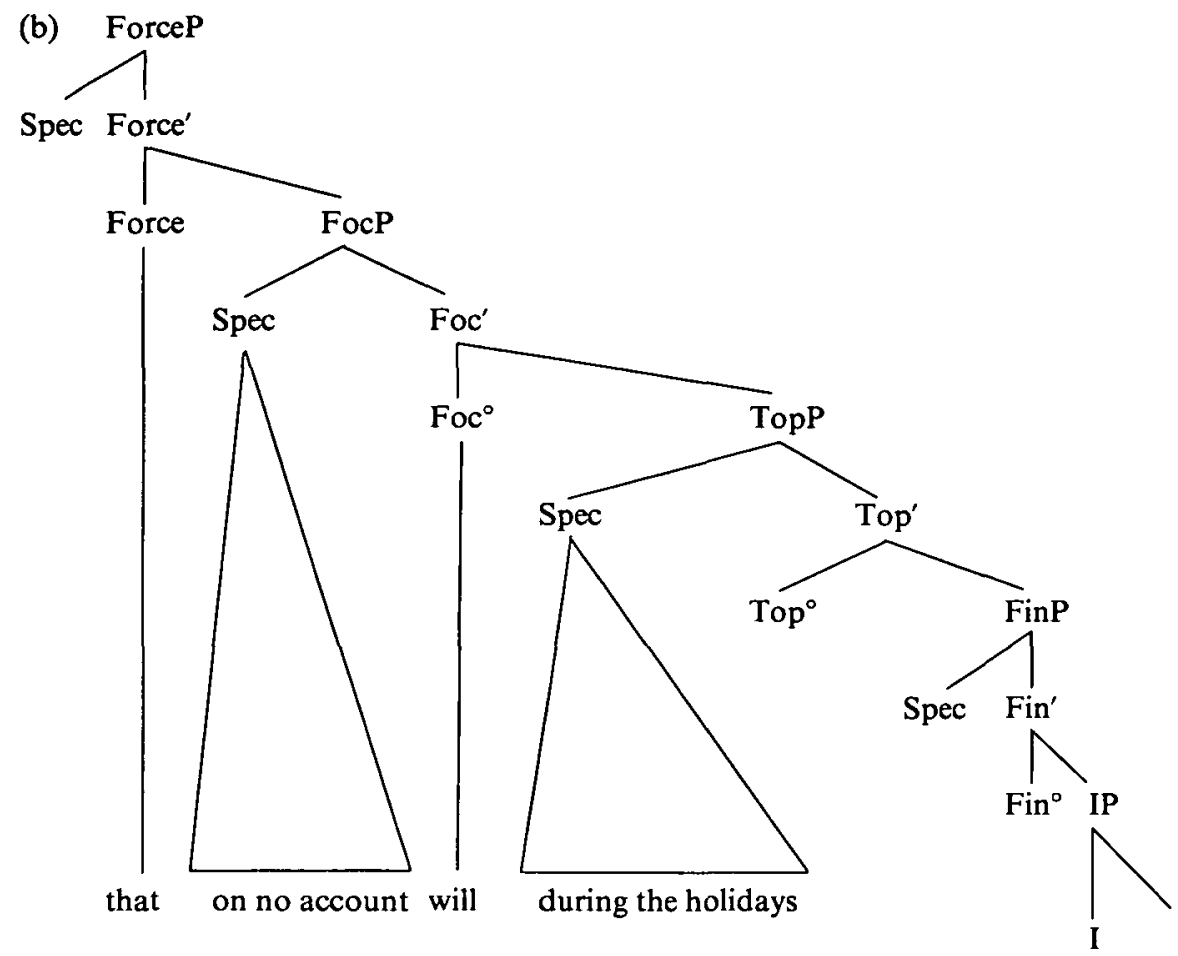

\subsubsection{TopP}

From the evidence presented above, it seems reasonably clear that preposed constituents involve additional functional projections, hence that the IP-adjunction analysis must be abandoned. The analysis rests upon the split CP hypothesis: what originally was considered to be one projection ' $\mathrm{CP}$ ' is decomposed into a set of functional projections:

(47) ForceP

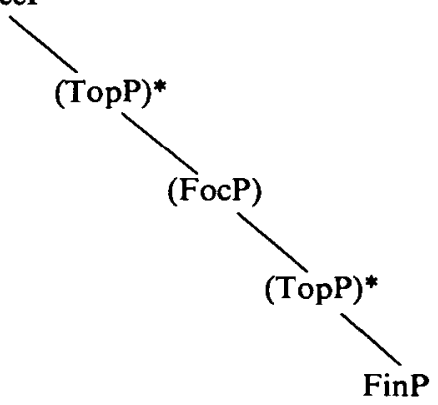

The split CP hypothesis has implications for truncation theory discussed in section 2.4.3. If truncation is free to apply at any level of the $\mathrm{CP}$ domain, it is conceivable, for instance, that what was originally $\mathrm{CP}$ is only partially truncated. We will see that ForceP may be truncated, leaving the lower projections available. 
Let us then return to the examples of what seem to be noninitial null subjects

(48) (a) Last week denounced Johnnie Cochran, ...

(Guardian, 4 October 1995, 'Cast of characters', p. 2 (cols. 1-2), p. 3 (cols. 7-8))

(b) puis se colle à moi (Léautaud, Journal particulier, 1933, p. 31) then clings to me

If the topicalized adjuncts last week and puis ('then') are associated with a full projection, then the antecedentless empty category will not be able to survive in the specifier of IP. Even if ForceP is truncated, the specifier of TopP will still be available for a potential antecedent. The tree in (49) would be the relevant representation for the data.

(49)

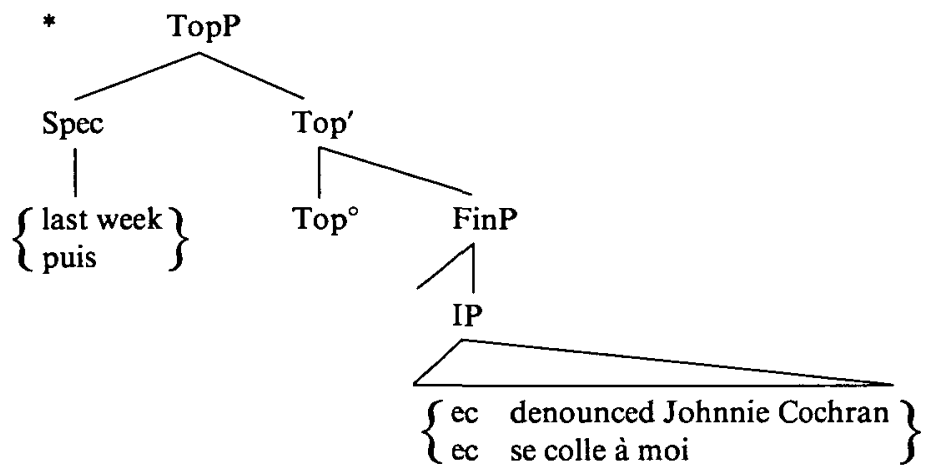

In (49), last week/puis, in [Spec, TopP], is a potential antecedent for the empty category in the subject position. Puis/last week c-commands the trace in [Spec, IP], hence the antecedentless nonvariable empty category has a potential binder. Coindexation of last week/puis and the trace leads to ungrammaticality; if the trace and last week/puis are not coindexed the sentence violates the ECP.

\subsection{Bypassing the adjunct in the CP domain}

What I would like to suggest in this section is that (49) is not the appropriate representation for the problematic sentences in (48) and that the nonovert subject is not to the right, but rather to the left of the preposed adjunct, leaving a coindexed trace in the canonical subject position:

(50) (a) ec $\mathrm{c}_{\mathrm{i}}$ Last week $\mathrm{t}_{\mathrm{i}}$ denounced Johnnie Cochran, ...

(Guardian, 4 October 1995, 'Cast of characters', p. 2 (cols. 1-2), p. 3 (cols. 7-8))

(b) $\mathrm{ec}_{\mathrm{i}}$ Puis $\mathrm{t}_{\mathrm{i}}$ se colle à moi (Léautaud, Journal particulier, 1933, p. 31)

then clings to me

One component that will bear on the analysis is the incompatibility of NSDs with argument topicalization:

(51) (a) *More problems don't need. (Thrasher, 1977: 83)

This means that our analysis must exclude representations (51b) and (51c): 
(51) (b) *More problems ec don't need.

(c) ${ }^{*} e c_{i}$ more problems $t_{i}$ don't need.

Example (51b) is excluded as before: the antecedentless empty category is illicit because it has a potential antecedent (more problems).

The representations in (50) suggest that an antecedentless null subject must be able to bypass a preposed adjunct while not being able to cross a preposed argument. The observed adjunct/argument asymmetry is independently attested in sentences with subject extraction. In (52a) the interrogative pronoun qui is the subject of the embedded clause. It has been extracted from the embedded clause to the matrix domain. It has bypassed the preposed adjunct. In (52b) the bypassing is blocked when an argument is preposed.

(52) (a) Qui crois-tu qui l'année prochaine pourra nous aider? who think-you that year next will-be-able us help 'Who do you think that next year will be able to help us?'

(b) *Qui crois-tu qui ton livre, pourra l'acheter? who think-you that your book will-be-able it to buy 'Who do you think that will be able to buy your book?'

Let us first examine such examples of long $w h$-movement of the subject. The contrast in French (53) is well known from the literature (Rizzi, 1997: 319, his (111)):

(53) (a) *Voici l'homme que je crois que t pourra nous aider l'annee prochaine. this is the man that I think that can-fut. us help year next

(b) Voici l'homme que je crois qui t pourra nous aider l'année prochaine.

The standard analysis of the contrast in (53) is that in (53a) the complementizer que, like that in English, is inert for head government; the subject trace violates the government condition of the ECP. In (53b) qui is the spell-out of the agreeing complementizer which can head-govern the subject trace (see (4b, c), (42a)). Rizzi (1997: 319) observes that the interpolation of an adjunct topic in (54a) does not lead to any difference in judgement, while when an argument is topicalized (54b) there is a strong degradation.

(54) (a). Voici l'homme que jecrois qui l'année prochaine pourra nous aider. this is the man that I think that year next will-be-able us help 'This is the man who I think that next year will be able to help us'

(b) ??*Voici l'homme que je crois qui ton livre, pourra l'acheter. this is the man who I think that your book will-be-able it to buy 'This is the man who I think that will be able to buy your book'

Leftward wh-movement of the subject can bypass a preposed adjunct without creating ECP violations, while it cannot legitimately bypass an object.

In order to account for the data Rizzi (1997: 320) proposes a further elaboration of the functional system in the CP domain. He assumes that in general the head of a substantive (contentful) functional projection, 'FP', may freely be associated with AGR features, and that this association will license an agreement projection which immediately dominates FP. The features of the head of the dominating agreement 
projection will match the AGR features of $\mathrm{F}^{\circ}$. Applied to the CP domain, Top ${ }^{\circ}$ may host AGR features and TopP may be dominated by an associated AgrP.

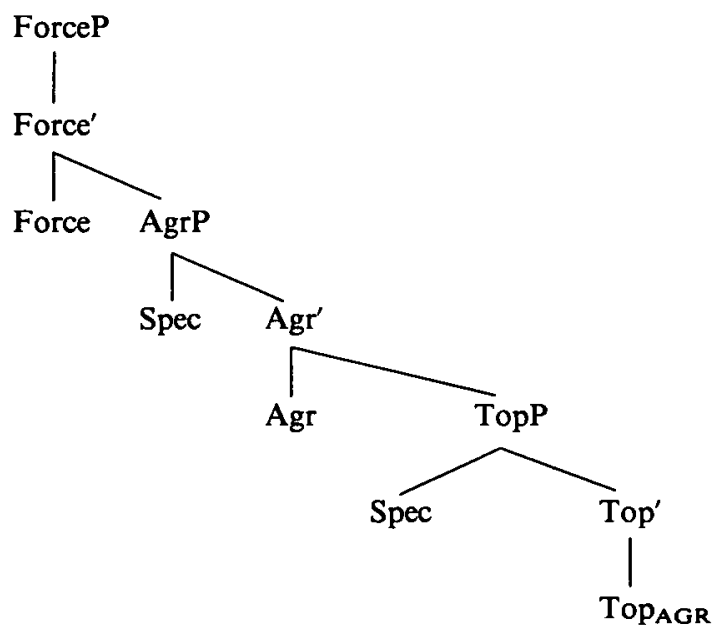

In a further refinement of the analysis of preposing, Rizzi proposes that adjuncts do not move into the specifier of TopP, but adjoin to TopP. Adjunction to TopP does not activate the agreement features on Top. ${ }^{12}$ This means that the agreement features on $\operatorname{Top}^{\circ}$ and the agreement projection dominating TopP are still available. Specifically, the specifier of the Agr-Projection can be a landing site for (A-) movement. Suppose that the subject moves via the specifier of FinP, bypasses the preposed topic and moves into the specifier of the AgrP. Carrying agreement features, the subject will activate the agreement head Agr. The features of Agr match those on Top. Top AGR can head-govern the intermediate subject trace in the specifier of FinP. The intermediate trace in FinP in turn triggers agreement on Fin ${ }^{\circ}$, which can head-govern the subject trace in [Spec, IP].

The situation is different when an argument is preposed. Rizzi proposes that arguments move into the specifier of TopP. Suppose Top is associated with agreement features. The preposed argument in [Spec, TopP] carries agreement features. The argument in the specifier of TopP will trigger the agreement on Top and this will exhaust the agreement features on Top. Even if an agreement projection is projected on top of TopP, the subject will not be able to move through [Spec, AgrP]. The agreement features on Top match those of the argument in its specifier. Two problems arise. First, if the subject were to move into [Spec, AgrP] and trigger agreement there, the features of Agr would not match those of Top clash would imply that AgrP is licensed independently from TopP, contrary to the assumption developed here. Moreover, the subject trace in [Spec, FinP] cannot be governed by the head Top AGR, since the agreement features of this head do not match those of the subject. I refer to a full discussion in Rizzi (1997).

12 An alternative view would be to say that adjuncts do move into the specifier of TopP but that since they do not carry Agr features they do not activate Agr on Top. 
(56)

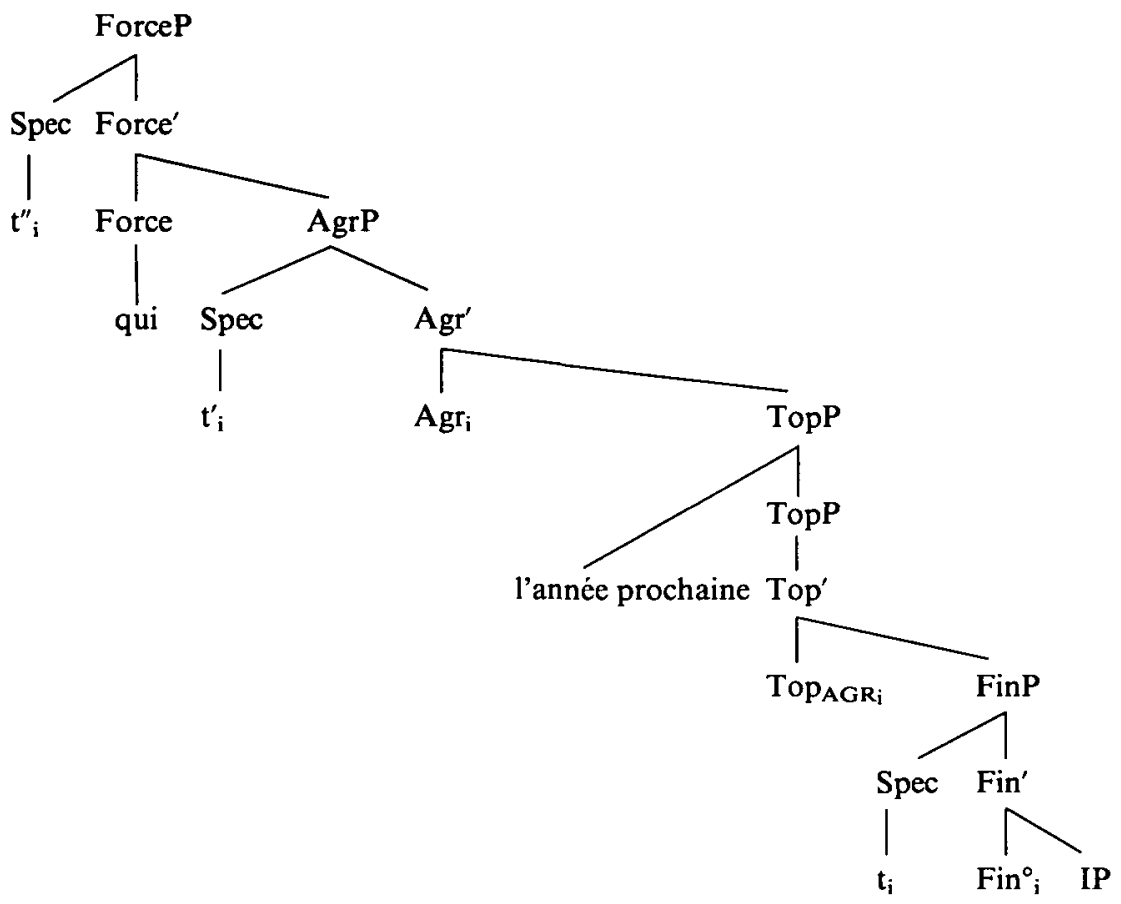

(57)

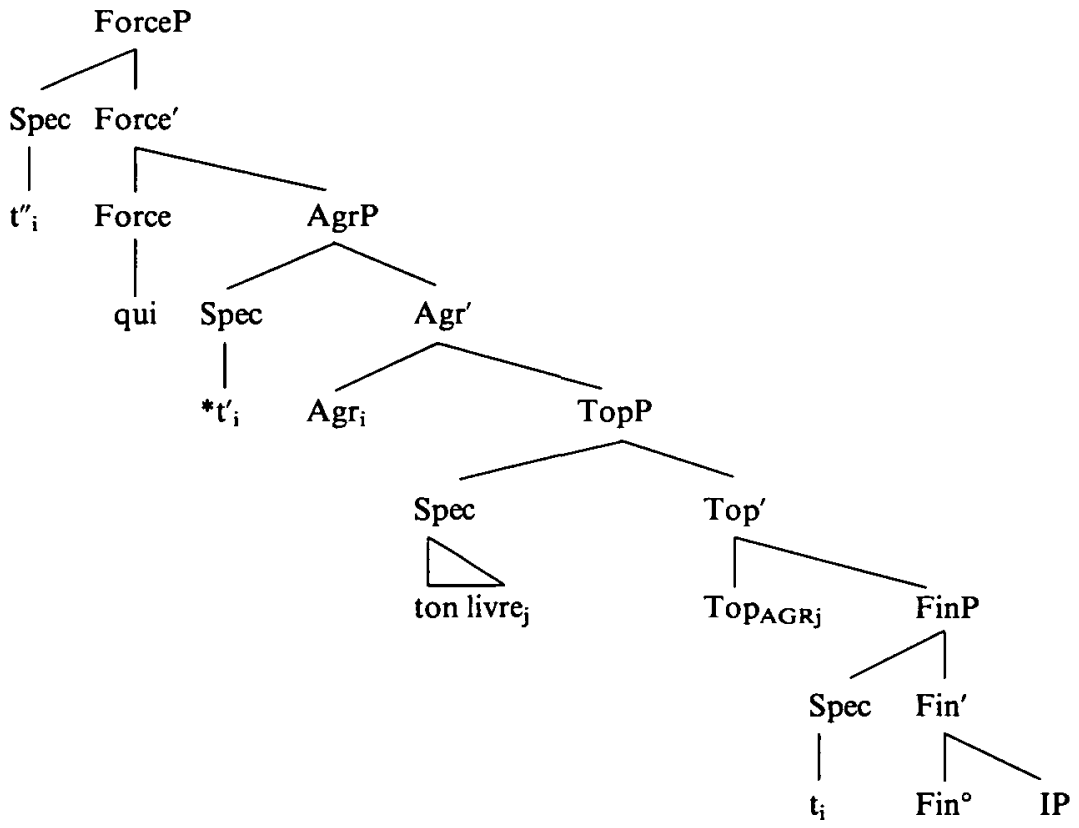

The subject can bypass a preposed adjunct, though not a preposed object:

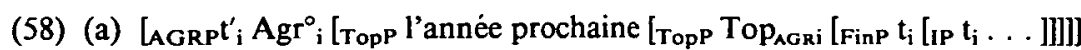

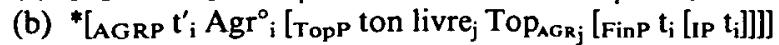


Suppose now that in the A-specifiers of the functional projections (AgrP) of the examples in (58), we insert an antecedentless nonvariable empty category. Example (59a) would be a grammatical NSD sentence; (59b) is ungrammatical. The adjunct/ argument asymmetry of (58) is maintained:

(59) (a) (Cette année Jean est en congé.) L'année prochaine, pourra nous aider. 'This year Jean is on leave. Next year, will be able to help us.'

(b) "Ton livre, pourra l'acheter. your book will-be-able it to buy

Example (59a) has the structure (60a). In the absence of higher structure, the ec in the specifier of the root, the AgrP dominating and licensed by TopP, may remain antecedentless.

(60) (a)

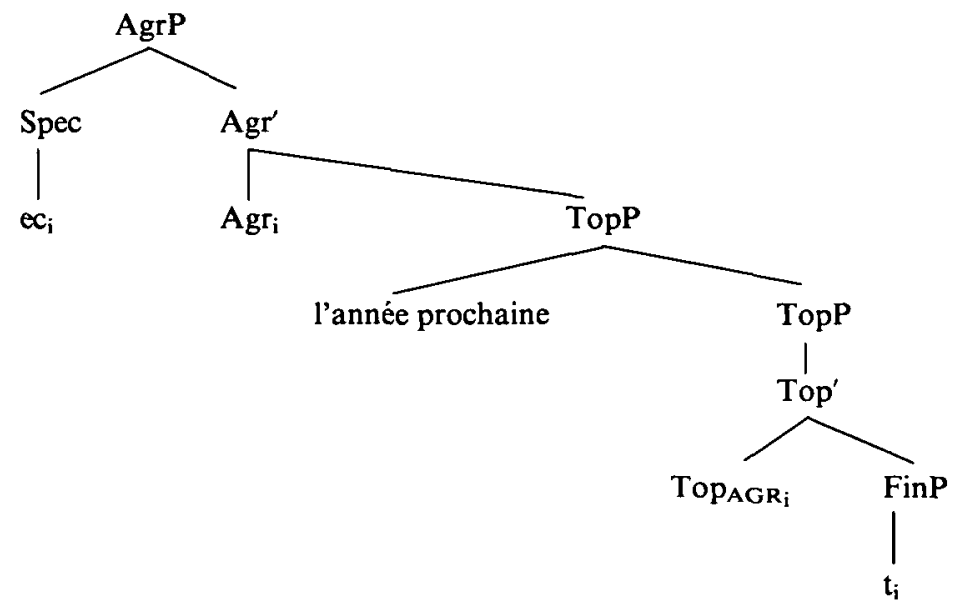

Example (59b) is parallel to (58b): the antecedentless empty category cannot bypass the preposed object in the same way that the $w h$-constituent in (58b) cannot bypass the preposed object.

(60) (b)
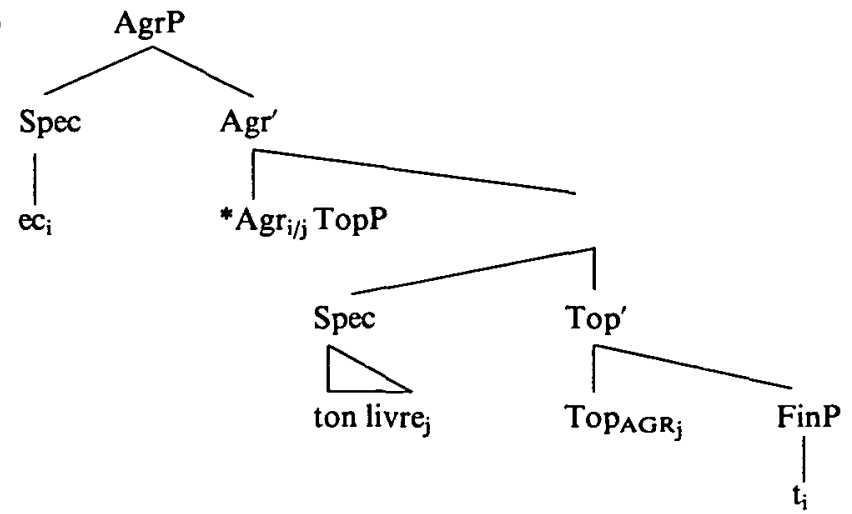
Observe that for this account to work we must assume that in (60a) there is no projection dominating AgrP. If ForceP were projected, the specifier of ForceP would provide a position for the antecedent of the trace in [Spec, AgrP] and the identification condition of the ECP (28) would come into play:

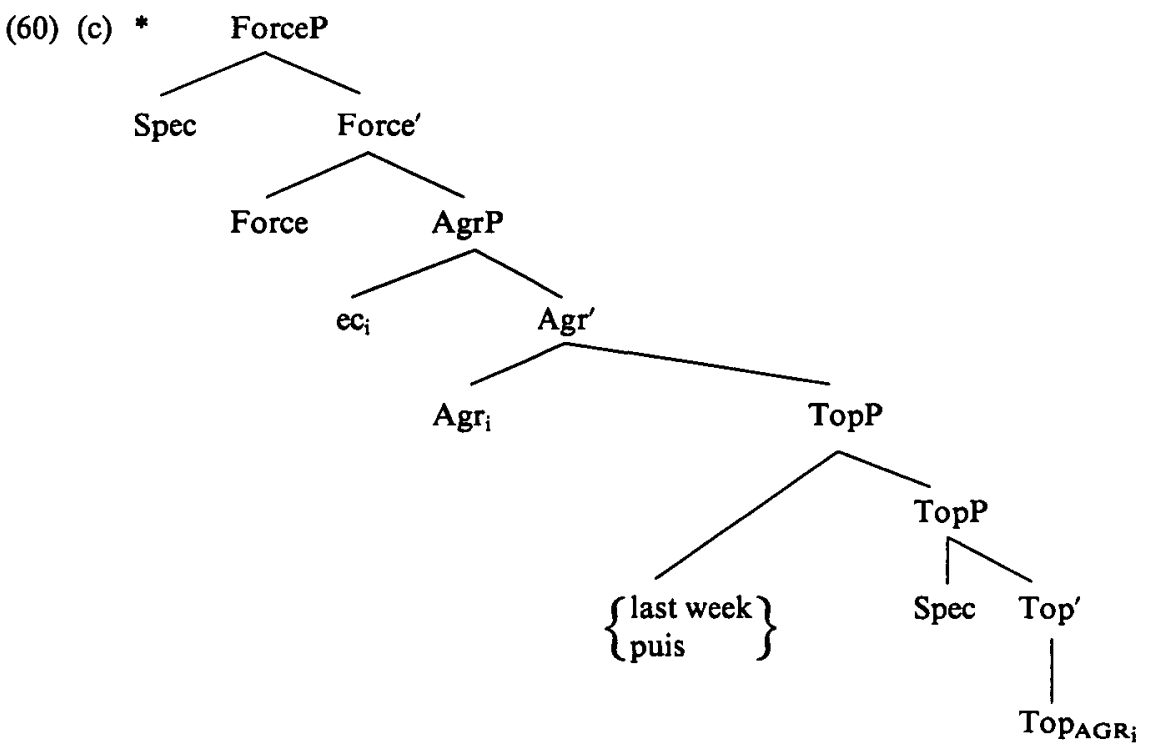

In the analysis developed above, the null subject thus depends on truncation of functional structure: ForceP is truncated. My analysis departs slightly from Rizzi's original proposal (1994): he proposed complete CP truncation. In my account partial truncation of some of the projections of the CP domain (here ForceP) must be allowed.

Given the analysis above, the problem of the apparently noninitial NSD disappears. By analogy with the examples of subject $A^{\prime}$-movement, we have postulated a representation where the null subject bypasses the adjunct and cannot bypass the topicalized object.

The other constraints on the distribution of NSDs follow from the analysis. Embedded NSDs remain excluded: in such cases the matrix domain will provide antecedent positions, rendering antecedentless nonovert subjects illicit by (28). NSDs remain excluded in wh-questions see $(16 \mathrm{~b}, \mathrm{c})$. As can be seen in (61), subject $w h$-movement cannot bypass the preposed adjunct wh-phrase. I assume that whphrases move to the CP domain and enter into an agreement relation with a head carrying the $w h$-feature. This agreement exhausts the possibilities of agreement on the relevant head just as in the case of argument preposing. The relevant head in this particular case would not be the Top ${ }^{\circ}$ but the focal head. I refer the reader to Haegeman (1995) for detailed discussion. 
(61) (a) * Who do you wonder when will come back?

(b) *Qui te demandes-tu quand reviendra? who yourself ask-you when will return

An alternative approach to the data in $(16 \mathrm{~b}, \mathrm{c})$ might be to say that in wh-questions ForceP is obligatorily projected to mark the interrogative force of the clause, and hence the antecedentless empty category in the CP domain will violate the ECP (29b). This cannot be correct, though, as shown by the data in (62). I assume that negative inversion leads to a specifier-head relation between the preposed negative constituent and the auxiliary. In such cases too NSD cannot survive.

(62) (a) Never again did I talk to him.

(b) *Never again did talk to him.

It would be hard to maintain that in sentences with negative inversion ForceP must be projected.

\subsection{Principle C effects}

The analysis outlined so far leads to certain predictions with respect to the interpretation of the null subject. ${ }^{13}$ If, as I assume, the null subject bypasses a preposed adjunct, and moves to a c-commanding A-position, then the expectation is that from that higher position, the null subject will act as a binder for lower Apositions. Notably, the null subject in the specifier of the higher AgrP would be a binder for any DP contained within the preposed adjunct. The data in (63) and (64) in fact confirm this expectation, both for French and for English:

(63) (a) Sur cette photo de Marie i $_{\text {, }}$ elle $e_{i}$ sourit. on this picture of Marie she smiles

(b) $\left[\mathrm{ec}_{\mathrm{i}}\right.$ [Sur cette photo de Marie $\mathrm{e}_{\mathrm{i}}\left[\mathrm{t}_{\mathrm{j} / \star_{\mathrm{i}}}\right.$ sourit]]]

(64) (a) In John's picture of Mary , she $_{i}$ smiles.

(b) [ec $\mathrm{ec}_{\mathrm{i}}$ [In John's picture of Mary,$\left.\left.\left[\mathbf{t}_{\mathrm{j} / *_{\mathrm{i}}} \mathrm{smiles}\right]\right]\right]$

Examples (63a) and (64a) allow coreference between the matrix subject, elle/she, and the DP contained in the adjunct, Marie/Mary; (63b) and (64b) are ungrammatical with coreference between the null subject and the DP. The Principle $\mathrm{C}$ effects observed in the above examples confirm the hypothesis developed here. They also bring out quite clearly that the null subject is not strictly equivalent to the pronominal counterpart.

13 Thanks to a reviewer of this paper for bringing this implication to my attention. As pointed out by the reviewer, (i) may not be felt to be as strong a Principle $C$ violation as the examples in section 4.4:

(i) Although John smokes, never touches alcohol.

The judgements are unclear: some of my informants rejected (i), others accepted it. A number of observations are pertinent. First, it is known that Principle $C$ violations get weaker when the R-expression is embedded in a sentence (Reinhart, 1981). Second, the structural position of the although sentence in (i) is not clear. It might occupy a more peripheral position than the preposed adjuncts in the text example (see Haegeman, 1984). 


\section{For further research}

\subsection{Speculations on be omission and truncation}

\subsubsection{Written registers}

Written registers offer another type of omission illustrated in the text example (8b), repeated here as (65).

(65) \& those the worst (Diary of Virginia Woolf, p. 33)

One tempting analysis for this phenomenon is to propose that these examples instantiate the English equivalent of the Russian independent be-less sentence in (66a) (see Aarts, 1992: 38-9). However, it is not clear that such an analysis is entirely adequate. In Russian, the left periphery of the be-less sentences is clearly available (66b-d), suggesting that such clauses are full-blown CP structures with a nonovert copula (see Kondrashova, 1996). ${ }^{14}$

(66) (a) Kolja nash uchitel.

Kolja our teacher

'Kolja is our teacher.'

(b) Pochemu Kolja nash uchitel? why Kolja our teacher 'Why is Kolja our teacher?'

(c) Segodnja Kolja nash uchitel. today Kolja our teacher 'Today Kolja is our teacher.'

(d) Verojatno Kolja nash uchitel. probably Kolja our teacher 'Probably Kolja is our teacher.'

So far I have not come across any examples of wh-preposing with be-less sentences as in (67) in the written corpus which I have examined.

(67) \%*Why John sick?

Nor have I come across examples with be-deletion in sentences with adverb preposing. It would seem that while the be-less clause is compatible with an adjunct, this adjunct may not prepose:

(68) (a) \%Leonard probably angry.

(b) \%*Probably, Leonard angry.

Argument preposing is also unattested:

(69) (a) \%John not even aware of this problem.

(b) *\% This problem, John not even aware of.

(c) $\%{ }^{*}$ Of this problem, John not even aware.

The same restrictions seem to extend to French.

\footnotetext{
14 Thanks to Natalia Kondrashova for generous help with the Russian data.
} 
(70) (a) \%Pierre fâché.

Pierre angry

(b) \%*Pourquoi Pierre fâché?

why Pierre angry

(c) \%Pierre probablement fâché.

Pierre probably angry

(d) \%*Probablement, Pierre fâché.

The distribution of be-less sentences in written registers is subject to further research. I will assume at this point that the absence of preposing in such sentences is a genuine phenomenon. On this basis, I will outline a first analysis for the $b e$-less sentences.

Following recent analyses of small clauses by Aarts (1992) and by Starke (1994), I assume that small clauses in general are not simply projections of a lexical head but that they contain functional structure. Aarts (1992: 174) provides the following evidence:

(71) (a) I thought [it perhaps a pity at the time]

(b) I must admit that I have found [these summer international schools probably the most rewarding part of my work]

Aarts (1992: 175) says: 'As adverbials with sentential scope do not occur in phrasal expansions of lexical categories we must conclude that the bracketed sequences in [71] are not NPs.' The native speakers I consulted consider the medial sentence adverbial grammatical in independent be-less sentences in special registers, suggesting that these too involve more functional structure. The grammaticality of the medial adverbial in English (68a) and French (70c) suggests that the be-less sentences contain functional projections of the IP domain. This conclusion differs from that proposed by Radford (1990), who assumes that small clauses are lexical projections.

While nonovert be in Russian is apparently licensed in the presence of the full $\mathrm{CP}$ structure, the incompatibility of preposing and be-deletion in English and French abbreviated registers leads me to formulate the hypothesis that in these languages $b e$-omission is dependent on truncation. It could be proposed that be-less sentences contain a nonovert be in a functional head position (I or AgrS, following the split INFL). Assume that the null copula is subject to the identification condition of the ECP (28): ${ }^{15}$ it will only be licit when there are not higher heads. The highest functional head of IP will be the highest head in the structure provided the CPdomain is truncated. I will develop this point in future work. ${ }^{16}$

15 This means that (28) is extended to apply to an empty category both of the XP and of the $X^{\circ}$ type.

${ }^{16}$ For Russian an independent licensing mechanism would have to be assumed. The null operator in the core grammars of Portuguese, German, Chinese, etc. must presumably be licensed by some languageparticular property, probably of the CP system. In the same way, we propose that the null be of Russian and similar languages is related by some property of the $C$ system.

A reviewer asks what the effect of truncation would be in pro drop languages. Obviously, the availability of null subjects in diaries is not to be seen as evidence for truncation since null subjects are available in the core grammar. However, be-less sentences such as (i) are evidence for truncation: 


\subsubsection{Be omission in early production}

$\mathrm{Be}$-omission is also a property of early production.

(72) (a) Lisa naughty. (Hayley 20 months, Radford, 1990: 156)

(b) Wayne in bedroom. (Daniel 21 months, ibid., 157)

(c) Wayne sitting gate. (Daniel 21 months, ibid., 159)

Radford (1990) proposes that such be-less sentences correspond to pure lexical projections without functional projections. Example (72a) is an AP; (72b) a PP; (72c) a VP. However, as signalled by Radford (1990), the relevant be-less sentences can contain a marker of negation:

(73) (a) Wayne not eating it. (Daniel 23 months, Radford, 1990: 152)

Radford proposes that the negative marker in the be-less small clause is adjoined to the lexical projection. He would propose the same analysis for the negative marker in the embedded small clause in (73b):

(73) (b) I find [your behaviour not compatible with your position] (see Radford, 1990: 153)

If we follow Aarts (1992) and Starke (1994) in assuming that small clauses are functional projections, then an alternative analysis suggests itself for the early be-less sentences. The be-less sentences in the child grammar can again be assumed to be parallel to the be-less sentences in the abbreviated registers and correspond to IPs with nonovert be. I will examine be-deletion in more detail in future work (see Haegeman, in preparation). ${ }^{17}$

\subsection{Auxiliary deletion in informal English}

Another distinctive property of the noncore grammars of English is auxiliary drop, ${ }^{18}$ which may sometimes be accompanied by subject omission (see also Akmajian et al., 1980; Rizzi, 1994; Schmerling, 1973; Thrasher, 1977). Three types of auxiliary deletion have been discussed in the literature. I will provide a survey here. A full discussion of this phenomenon is outside the scope of the present paper.

\subsubsection{Subject + auxiliary omission in declaratives}

In declarative sentences in informal English (as well as in the written abbreviated register) both subject and auxiliary may be deleted.

(74) (a) Forgotten what I was supposed to do.

(i) (a) Gianni ammalato. Gianni sick

(b) Maria partita. Maria gone

17 Obviously, not all phenomena of the early grammar are found in the abbreviated registers. The independent use of infinitival clauses as declaratives which is a property of the child grammar is not attested in the adult grammar (see Haegeman, 1994b; Rizzi, 1995).

18 As pointed out by the two reviewers of an earlier version of this paper. 
In (74a), the omission of the auxiliary have is dependent on the omission of the subject:

(74) (b) \%*I forgotten what I was supposed to do.

The phenomenon illustrated above is again not simply reducible to a left edge phenomenon (75a). The comma intonation in (75a) confirms that frankly is an initial adverbial (cf. $(75 b-c)) .{ }^{19}$

(75) (a) Frankly, done no work.

(b) Frankly, I've done no work.

(c) I've frankly done no work

Again, though, subject and auxiliary will not be omitted together in $w h$-questions:

(75) (d) \%*Why forgotten what I had to do.

$\% *$ How often forgotten what I had to do.

As a first speculation I would like to propose that these cases of subject-auxiliary deletion involve the kind of subject deletion described in this paper with a further option of auxiliary deletion. I will pursue the phenomenon of subject + auxiliary deletion in future work.

\subsubsection{Auxiliary deletion in wh-questions}

In root $w h$-questions, the inverted auxiliary may be omitted in informal speech. Here auxiliary omission is not contingent on subject omission, and indeed subjact omission is not possible:

(76) (a) Where you going? What you doing?

(b) "Where going? What doing? ${ }^{20}$

Thrasher (1977) shows that auxiliary deletion in wh-questions is determined by phonological factors (see also Akmajian et al., 1980). ${ }^{21} \mathrm{He}$ discusses the following contrast:

(77) (a) $\% *$ What he gonna do?

(b) \% What she gonna do? (Thrasher, 1977: 22)

\subsubsection{Auxiliary + subject deletion in yes/no questions}

Finally, auxiliary deletion also takes place in yes/no questions.

(78) (a) (Are) You going to lunch? (Rizzi, 1994: 172)

(b) (Have) You ever been to Chicago?

19 Thanks to a reviewer of this paper for clarifying these data for me.

${ }^{20}$ Non-finite wh-questions introduced by why are an exception to this generalization:

(i) (a) Why go there?

(b) Why mention anything to anyone?

21 The early production of English has examples such as (i):

(i) What Kitty doing? (Radford, 1990: 134)

Radford (1990: 134) suggests that these structures are VPs with what in an adjoined position. Alternatively, one might assume that they are $\mathrm{CPs}$ with a null auxiliary. 
(c) (Would) Your wife be offended if I smoke? (Thrasher, 1977: 18)

(d) (Is) Bill busy? (ibid., 41)

(e) (Are) You a school teacher? (ibid., 41)

To account for the auxiliary deletion in inverted contexts, Rizzi (1994: 172) suggests that 'I-to-C movement raises the AUX to the root head, where it can be null under our interpretation of [28].'

In yes/no questions with auxiliary deletion, the subject may also delete (79a). In such cases, subject deletion is contingent on auxiliary deletion, as shown by the ungrammaticality of (79b) (see Schmerling, 1973: 580):

(79) (a) Going to lunch?

(b) *Are going to lunch?

In general it is second-person subjects which delete with the auxiliary in yes/no questions (see Schmerling, 1973: 580). Akmajian et al. (1980: 192) point out that 'the second-person subject you can be deleted as long as an auxiliary verb is contracted to it'. Rizzi proposes that 'the possibility of dropping a second person pronoun in this environment may involve incorporation of the pronoun into the null auxiliary, and/or be akin to the null subject of imperatives' (1994: 172, n. 11).

Observe, though, that auxiliary + subject deletion is not absolutely restricted to second-person subjects. Thrasher points out instances of the deletion of a first-person subject:

(80) (a) (Can I) Use your phone? (Thrasher, 1977: 89)

(b) (Can I) Borrow your hedge-clippers? (ibid.)

Schmerling (1973: 580) provides the following example of third-person subject deletion:

(80) (c) (Does that) sound okay to you?

With respect to the deletion of both the subject and the auxiliary in declaratives and in yes/no interrogatives there is a linear dependency relation in that the deletion of the rightmost constituent, the subject in yes/no questions, and the auxiliary in declaratives, is contingent on the deletion of the constituent to its immediate left, the preposed auxiliary in yes/no questions and the subject in declaratives.

In the same way that subject + auxiliary deletion in declaratives was not confined to the leftmost periphery of the clause, auxiliary + subject deletion in yes/no questions is not absolutely restricted to the left periphery:

(81) (a) After class, you going to be free?

(b) After class, going to be free?

I intend to return to the deletion of auxiliary and subject in future work.

\section{Conclusion}

In this paper I have considered null subject phenomena in French and English. Though non-pro-drop languages, French and English allow for nonovert subjects in 
certain registers and also in early production. I have assumed that this is a grammatical phenomenon and that the null subjects are antecedentless empty categories in the specifier of the root. In order for the antecedentless empty category to survive in the specifier of the root, I assume, following Rizzi (1994), that the clause structure may be truncated.

The prediction of the analysis would be that null subjects must be the leftmost constituents in the structure. There are apparent exceptions to this generalization, i.e. cases where the subject is preceded by an adjunct. However, I show that these cases can be reinterpreted: the nonovert subject in fact precedes the preposed adjunct, it occupies the specifier of an agreement projection licensed by and dominating TopP and binds the trace in the canonical subject position. The examples can be aligned with instances of subject extraction across adjuncts. Movement to [Spec, AgrP] can bypass preposed adjuncts; movement to [Spec, AgrP] cannot bypass preposed arguments. In order for the truncation analysis to be maintained we have to extend Rizzi's original proposal and allow for partial truncation of CP. In the last section of the paper I have considered other properties of the abbreviated and informal registers. I have suggested how the truncation analysis may also provide the tools to account for be-less sentences in written registers. Finally, I have provided a brief description of the auxiliary deletion phenomenon.

Author's address:

Department of Linguistics

University of Geneva

CH 1211 Geneva 4

Switzerland

haegeman@uni2a.unige.ch

\section{Corpus material}

Diaries

Léautaud, P. (1989). Le Fléau. Journal particulier, 1917-1939. Paris: Mercure de France.

Pepys, S. (1985). The shorter Pepys. Ed. Robert Latham. London: Penguin.

Smart, E. (1992). Necessary secrets. Ed. Alice Van Wart. London: Paladin/Harper Collins.

Smart, E. (1995). On the side of the angels. London: Flamingo/Harper Collins.

Woolf, V. (1985). The diary of Virginia Woolf, vol. V: 1936-1941, ed. A. O. Bell, assisted by

A. McNeillie. London: Penguin.

\section{Fiction}

Rendell, R. (1994). A sleeping life: an Inspector Wexford mystery. London: Arrow.

Symons, J. (1967). The Julian Symons omnibus. London: Crime Club.

Symons, J. (1973). The plot against Roger Rider. London: Penguin. 


\section{References}

Aarts, B. (1992). Small clauses in English: the nonverbal types. Berlin and New York: Mouton de Gruyter.

Akmajian, A., R. A. Demers, \& R. M. Harnish (1980). Linguistics. Cambridge, MA: MIT Press.

Arimura, K. (1995). Object empty categories and coordinate structure in earlier English. The Konan Journal of English Studies 92: 1-34.

Bloom, P. (1990). Subjectless sentences in child language. Linguistic Inquiry 21: 491-504.

Bresnan, J. (1977). Variables in the theory of transformations. In Culicover, P. (ed.), Formal syntax. New York: Academic Press. 157-96.

Bromberg, H. \& K. Wexler (1995). Null subjects in wh-questions. In Schütze, C. T., J. B. Bandner, \& K. Broihier (eds.), Papers on Language Processing and Acquisition, MIT Working Papers in Linguistics 26: 221-47.

Browning, M. (1996). CP recursion and that-t effects. Linguistic Inquiry 27: 237-56.

Cardinaletti, A. \& M. Starke (1993). On dependent pronouns and pronoun movement. Paper presented at the GLOW Conference, Lund.

Chomsky, N. (1991). Some notes on the economy of derivation. In Freidin, R. (ed.), Principles and parameters in comparative grammar. Cambridge, MA: MIT Press. 417-54.

Chomsky, N. (1995). The minimalist program. Cambridge, MA: MIT Press.

Cinque, G. (1991). Types of $A^{\prime}$-dependencies. Cambridge, MA: MIT Press.

Cinque, G. (1995). Adverbs and the universal hierarchy of functional projections. GLOW paper, Tromsö.

Culicover, P. (1991). Topicalization, inversion and complementizers in English. In Delfitto, D., M. Everaert, A. Evers, \& F. Stuurman (eds.), OTS working papers: going Romance and beyond. Utrecht: Department of Linguistics, University of Utrecht. 1-45.

Enç, M. (1987). Anchoring conditions for tense. Linguistic Inquiry 18: 633-58.

Friedemann, M.-A. (1992). The underlying position of external arguments in French: a study in adult and child grammar. Geneva Generative Papers 0.1-2: 123-44.

Guéron, J. (1993). Sur la syntaxe du temps. Langue Franfaise 100: 102-24.

Guéron, J. \& T. Hoekstra (1988). T-chains and the constituent structure of auxiliaries. In Cardinalettti, A., G. Cinque, \& G. Guisti (eds.), Constituent structure. Dordrecht: Foris. 35-99.

Guéron, J. \& T. Hoekstra (1992). Chaînes temporelles et phrases réduites. In Obenauer, H. G. \& A. Zribi-Herz (eds.), Structure de la phrase et théorie du liage. Vincennes: Presses Universitaires de Vincennes. 69-91.

Haegeman, L. (1984). Remarks on adverbial clauses and definite anaphora. Linguistic Inquiry 15: 715-19.

Haegeman, L. (1988). Register variation in English: some theoretical observations. Journal of English Linguistics 20: 230-48.

Haegeman, L. (1990a). Non-overt subjects in diary contexts. In Mascaro, J. \& M. Nespor (eds.), Grammar in progress. Dordrecht: Foris. 165-74.

Haegeman, L. (1990b). Understood subjects in English diaries. Multilingua 9: 157-99.

Haegeman, L. (1994a). Introduction to government and binding theory. 2nd edn. Oxford: Blackwell.

Haegeman, L. (1994b). Root infinitives, Tense and truncated structures. Geneva Generative Papers 2.2: 12-41.

Haegeman, L. (1995). Null subjects in the non-pro-drop languages. Paper presented at Going Romance. MS, University of Geneva.

Haegeman, L. (1996). Root infinitives, Tense and truncated structure in Dutch. Language Acquisition 4: 205-55. 
Haegeman, L. (ed.) (1997a). Elements of grammar: a handbook of generative syntax.

Dordrecht: Kluwer.

Haegeman, L. (ed.) (1997b). The new comparative syntax. London: Longman.

Haegeman, L. (in preparation). Be-deletion in specialized registers.

Hamann, C., L. Rizzi, \& U. Frauenfelder (1996). On the acquisition of the pronominal system in French. In Clahsen, H. (ed.), Generative perspectives on language acquisition. Amsterdam: John Benjamins. 309-34.

Huang, J. (1984). On the distribution and reference of empty pronouns. Linguistic Inquiry 15: 531-74.

Hyams, N. (1986). Language acquisition and the theory of parameters. Dordrecht: Reidel.

Hyams, N. \& K. Wexler (1993). On the grammatical basis of null subjects in child language. Linguistic Inquiry 24: 241-59.

Jaeggli, O. \& K. Safir (1989). The null subject parameter. Dordrecht: Kluwer.

Kondrashova, N. (1996). The syntax of existential quantification. Ph.D. dissertation, Wisconsin-Madison.

Lasnik, H. \& M. Saito (1984). On the nature of proper government. Linguistic Inquiry 14: 235-98.

Lasnik, H. \& T. Stowell (1991). Weakest crossover. Linguistic Inquiry 22: 687-720.

Massam, D. \& Y. Roberge (1989). Recipe context null objects in English. Linguistic Inquiry 20: $134-9$.

Müller, G. \& W. Sternefeld (1993). Improper movement and unambiguous binding. Linguistic Inquiry 24: 461-507.

Nakajima, H. (1996). Complementizer selection. Linguistic Review 13: 143-64.

Perlmutter, D. (1971). Deep and surface structure constraints in syntax. New York: Holt, Rinehart, and Winston.

Pesetsky, D. (1995). Zero syntax. Cambridge, MA: MIT Press.

Pierce, A. (1989). On the emergence of syntax: a crosslinguistic study. Ph.D. dissertation, Cambridge, MA: MIT.

Radford, A. (1990). Syntactic theory and the acquisition of syntax. Oxford: Blackwell.

Raposo, E. (1986). The null object in European Portuguese. In Jaeggli, O. \& C.

Silva-Corvalan (eds.), Studies in Romance linguistics. Foris: Dordrecht. 373-90.

Reinhart, T. (1981). Definite NP-anaphora and C-command domains. Linguistic Inquiry 12: 605-35.

Rizzi, L. (1982). Issues in Italian syntax. Dordrecht: Foris.

Rizzi, L. (1986). Null objects in Italian and the theory of pro. Linguistic Inquiry 17: 501-58.

Rizzi, L. (1990). Relativized minimality. Cambridge, MA: MIT Press.

Rizzi, L. (1991). Proper head government and the definition of A positions. GLOW, Leiden.

Rizzi, L. (1993). A parametric approach to comparative syntax: properties of the pronominal system. English Linguistics 10: 1-27. Also in Haegeman, L. (ed.), The new comparative syntax. London: Longman, 1997b: 268-85.

Rizzi, L. (1994). Early null subjects and root null subjects. In Hoekstra, T. \& B. Schwartz (eds.), Language acquisition studies in generative grammar. Amsterdam: John Benjamins. 151-77.

Rizzi, L. (1995). Some notes on linguistic theory and language development: the case of root infinitives. Language Acquisition 3: 371-93.

Rizzi, L. (1997). The fine structure of the left periphery. In Haegeman, L. (ed.), Elements of grammar: a handbook of generative syntax. Dordrecht: Kluwer. 281-337.

Roeper, T. \& B. Rohrbacher (1994). Null subjects in early child English and the theory of economy of projection. MS, University of Massachusetts at Amherst and University of Pennsylvania. 
Ross, J. R. (1982). Pronoun deleting processes in German. Paper presented at the Annual Meeting of the Linguistics Society of America, San Diego, California.

Schmerling, S. (1973). Subjectless sentences and the notion of surface structure. Chicago Linguistic Society 9: 577-86.

Starke, M. (1994). On the format for small clauses. Geneva Generative Papers 2.1: 79-97.

Stowell, T. (1991). Empty heads in abbreviated English. Paper presented at the GLOW conference, Leiden.

Thrasher, R. (1977). One way to say more by saying less: a study of so-called subjectless sentences. (Kwansei Gakuin University Monograph Series, 11.) Tokyo: Eihosha.

Valian, V. (1991). Syntactic subjects in the early speech of American and Italian children. Cognition 40: $21-81$.

Wilder, C. (1994). Some properties of ellipsis in coordination. Geneva Generative Papers 2.2: $23-61$. 